\title{
The Preconditioning of Lithium promotes Mesenchymal Stem Cell Based Therapy for the Degenerated Intervertebral Disc via Upregulating Cellular ROS
}

\section{Zemin Zhu}

Changxing People's Hospital

\section{Hongyuan Xing}

Zhejiang University School of Medicine Second Affiliated Hospital

\section{Ruofu Tang}

Zhejiang University School of Medicine Second Affiliated Hospital

\section{Shengjun Qian}

Zhejiang University School of Medicine Second Affiliated Hospital

Shaoqi He

Wenzhou Medical University Third Affiliated Hospital

Qiang Hu

Pujiang Tianxian orthopedic hospital

Ning Zhang ( $\nabla$ zhangning@zju.edu.cn )

Zhejiang University School of Medicine Second Affiliated Hospital https://orcid.org/0000-0003-29907442

\section{Research}

Keywords: lithium, adipose-derived stem cell, intervertebral disc degeneration, precondition, cell adaptation

Posted Date: November 19th, 2020

DOl: https://doi.org/10.21203/rs.3.rs-108512/v1

License: (1) This work is licensed under a Creative Commons Attribution 4.0 International License.

Read Full License

Version of Record: A version of this preprint was published at Stem Cell Research \& Therapy on April 14th, 2021. See the published version at https://doi.org/10.1186/s13287-021-02306-9. 


\section{Abstract}

\section{Background}

Adipose-derived stem cell (ADSC) is one of the most widely used candidate cell for intervertebral disc (IVD) degeneration. However, the poor survival and low differentiation efficacy in stressed host microenvironment limit the therapeutic effects of cell therapy. The preconditioning has been found effective to boost the proliferation and the functioning of stem cells in varying pathological condition. Lithium is a common anti-depression drug and has been proved effective to enhance stem cell functioning. In this study, the effects of preconditioning using $\mathrm{LiCl}$ on the cellular behavior of ADSC was investigated, and specially in a degenerative IVD-like condition.

Method

The cellular toxicity on ADSC was assessed by detecting lactate dehydrogenase (LDH) production after treatment with a varying concentration of lithium chloride $(\mathrm{LiCl})$. The proliferative capacity of ADSC was determined by detecting Ki67 expression and the relative cell number of ADSC. Then, the preconditioned ADSC was challenged by a degenerative IVD-like condition. Meanwhile the cell viability and the nucleus pulpous (NP) cell differentiation efficacy of preconditioned ADSC were evaluated by detecting the major markers expression and extracellular matrix (ECM) deposit.

Results

A concentration range of $1-10 \mathrm{mmol} / \mathrm{L}$ of $\mathrm{LiCl}$ was applied in the following study, since a higher concentration of $\mathrm{LiCl}$ causes a major cell death (about $40 \%$ ). The relative cell number was similar between preconditioned groups and the control group after preconditioning. The Ki67 expression was elevated after preconditioning. Consistently, the preconditioned ADSC showed stronger proliferation capacity. Besides, the preconditioned groups exhibit higher expression of NP markers than the control group after NP cell induction. Moreover, the preconditioning of $\mathrm{LiCl}$ reduced the cell death and promoted ECM deposits, when challenged with a degenerative IVD-like culture. Mechanically, the preconditioning of $\mathrm{LiCl}$ induced an increased cellular reactive oxidative species (ROS) level, which was found closely related to the enhanced cell survival and ECM deposits after preconditioning.

\section{Conclusion}

These results suggest that the preconditioning with a medium level of $\mathrm{LiCl}$ boosts the cell proliferation and differentiation efficacy under a normal or hostile culture condition via upregulating cellular ROS level. It is a promising pre-treatment of ADSC to promote the cell functioning and the following regenerative capacity.

\section{Introduction}


Low back pain (LBP) is one of the major causes of disability in the elderly.[1] The intervertebral disc degeneration (IVDD) is considered the main cause of LBP.[2] An alteration in the niche of nucleus pulpous (NP) cells results in cell death and the matrix imbalance of NP, with the denaturation of type II collagen (Col II) and the loss of glycosaminoglycan. Unfortunately, there is no ideal treatment so far. The current treatment includes conservative and surgical therapies, which cannot stop the degeneration process of IVD, nor reverse the degeneration.[3]

Cell based therapy has shown a great potential in the treatment of multiple diseases or pathological processes.[4] Because of the pluripotent property and an easy access, ADSC has attracted many attentions in bioengineering medicine. $[5,6]$ However, due to the harsh condition in degenerative intervertebral disc, the therapeutic effects of cell-based therapy is adversely limited, due to the poor survival and the impaired cell viability. Chan et.al reported only $20 \%$ of cells survived for over 7 days after transplantation into a simulated-physiological conditions of cryopreservation IVD.[7, 8] Specifically, previous researchers have proven that the acidic condition as well as high osmotic condition both impair the cell viability and proliferation, as well as the extracellular matrix (ECM) deposits.[1, 9-12] The urgent need of candidate cells that could adapt to IVD condition requires further study.

To promote the adaptation and the functioning of the transplanted cells in pathological condition, the preconditioning treatment has been developed and proved feasible,[13, 14] mainly including some chemical or biological factors. $[15,16]$ Due to the limited space in the degenerated disc, the preconditioned cell shows advantages of higher feasibility and integration, with lower chance to cause unexpected effects by implanted materials. Recently, the preconditioning using lithium has been found beneficial in cell based therapy against disease models in brain, bone and heart.[17-21]Lithium could promote the proliferation of bone marrow derived mesenchymal stem cell (BMSC) via a glycogen synthase kinase (GSK) 3 $\beta$-dependent $\beta$-catenin/Wnt pathway.[22] Besides, the preconditioning with Lithium has been found to reduce cell apoptosis by inducing autophagy.[23] Above studies suggest that the preconditioning of lithium would be a promising method to boost the cellular adaptation in a stressed microenvironment. While the specific influence of preconditioning with lithium to cellular adaptation of ADSC in the IVDD-like condition remains elusive.

In this regard, we designed this study to investigate the potential value of the preconditioning with lithium for an ADSC-based IVDD treatment. The cellular adaptation including cell proliferation, differentiation in normal or the IVDD-like condition were mainly evaluated.

\section{Materials And Methods}

\subsection{Cell culture and treatment}

The Sprague-Dawley (SD) rat ADSCs of passage 2 were purchased from Cyagen Bioscience (China). Cells were cultured using SD rat ADSC basal medium supplemented with $10 \%$ fetal bovine serum (FBS), $1 \%$ Glutamine and $1 \%$ penicillin-streptomycin. The medium was replaced twice every week, and cells at passages 4 were used in subsequent experiments. The ADSC microsphere was also prepared. Every $1 \mathrm{~mL}$ 
cell suspension containing $3 \times 10^{5}$ cells was added to $15 \mathrm{~mL}$ centrifuge tube, and centrifuge at $300 \mathrm{~g} / \mathrm{min}$ at $4{ }^{\circ} \mathrm{C}$ for $3 \mathrm{~min}$. The microsphere forms after incubation overnight.

In regard to the preconditioning treatment, ADSCs were implanted on 6-well plates at a density of $3 \times 10^{5}$ cells/well, and maintained overnight for adhesion. $\mathrm{LiCl}$ aqueous solution was added into basal medium at a final concentration of $0,1,4,10,20 \mathrm{mmol} / \mathrm{L}$. The cellular ROS production was blocked using apocynin (APO, $5 \mu \mathrm{M})$. Cells were maintained in LiCl-containing medium with or without APO for $48 \mathrm{~h}$ and washed with PBS.

The NP-like cell differentiation medium was built using the high glucose dulbecco's modified eagle medium (DMEM), supplemented with $10 \%$ FBS, Insulin-Transferrin-Selenium (ITS), dexamethasone (40 $\mathrm{ng} / \mathrm{mL}), 50 \mathrm{nM}$ ascorbic acid-2-phosphate, TGF- $\beta 3(10 \mathrm{ng} / \mathrm{mL})$, and IGF-1 (10 ng/mL).

The degenerative IVD-like condition was built according to previous reports.[24, 25] Briefly, the hyperosmotic condition ( $485 \mathrm{mOsm}$ ) was achieved by an addition of $2 \%$ potassium chloride $(0.1 \mathrm{M})$ and sodium chloride $(5 \mathrm{M})$, and the acidic condition ( $\mathrm{pH}=6.8$ ) was built with the $0.2 \%$ hydrogen chloride ( 1 M), which were added into the low glucose dulbecco's modified eagle medium (DMEM). [7, 24, 26]

\subsection{Cellular proliferation assay}

The cell viability was determined using a Trypan Blue staining reagent. The proliferation ability of ADSC after preconditioning was determined by counting the cell number and the lactate dehydrogenase (LDH) assay. The relative cell number was monitored using the cell counting kit (CCK8, dojindo) before treatment, after treatment, and at two days post-treatment. Briefly, cells were implanted in 96-well plate at a density of $1 \times 10^{4}$ cells/well. The supernatant was discarded, then the cells were incubated with $5 \%$ CCK8 in high glucose DMEM for 2 hours. The supernatant was collected and the absorption at $490 \mathrm{~nm}$ was detected using spectrophotometer. The LDH assay was performed according to the instruction of manufacturer. The culture medium was collected after preconditioning and two days after transplantation into the degenerative condition. The LDH content was determined by detecting the absorption at $440 \mathrm{~nm}$ was detected using spectrophotometer.

\subsection{Immunofluorescent staining}

The cell proliferation ability was also determined by detecting the Ki67 level after preconditioning. Briefly, cells cultured in 12-well plate were washed using cold PBS, and immobilized using $4 \%$ paraformaldehyde for $30 \mathrm{~min}$. Then cells were permeabilized using PBS-Triton (0.5\%) for $15 \mathrm{~min}$. After these, cells were blocked using $5 \%$ bovine serum albumin (BSA) at RT for $1 \mathrm{~h}$, and incubated overnight at $4{ }^{\circ} \mathrm{C}$ with Ki67 (ab15580) primary antibody.

After washing three times using PBS, the cells were incubated with secondary antibodies conjugated to the Alexa Fluor fluorescent dyes (ab150078). Subsequently washed with PBS, cells were stained with 4, 6- 
diamidino-2-phenylindole (DAPI, Sigma-Aldrich) for 5 min, and washed with PBS for observation. Images were captured using a fluorescent microscope.

\subsection{Western blot analysis}

Western blot analysis was performed to determine the protein content of major NP cell markers. Briefly, cells were washed three times with cold PBS and lysed at $4{ }^{\circ} \mathrm{C}$ using RIPA buffer (Beyotime) for 30 min. Protein contents were measured using the BCA protein assay. For each sample, $30 \mu \mathrm{g}$ total proteins were loaded and separated by sodium dodecyl sulfate polyacrylamide gel electrophoresis (SDS-PAGE) and transferred onto an immobilon polyvinylidene difluoride (PVDF) membrane (Millipore Billerica). The membranes were blocked using 10 \% bovine serum albumin (BSA) and incubated with anti-GAPDH antibody (CST\#5174), anti-type II collagen antibody (CST\#13120), anti-aggrecan antibody (CST\#13120) and anti-Krt19 antibody (CST\#12434), anti-SOX9 antibody (CST\#13120) overnight at $4{ }^{\circ} \mathrm{C}$. Then, the blots were rinsed and incubated with HRP-labeled secondary antibody (Bioker, China) for $2 \mathrm{~h}$ at room temperature (RT). The protein bands were visualized using a Bio-Rad imaging system, and the relative protein intensity of the control was calculated using "Quantity One” software.

\subsection{Gene expression analysis}

RT-PCR was performed to assess the mRNA level of the essential markers in the preconditioned ADSC under normal condition or IVDD condition after differentiation. Briefly, RNAiso reagent was used to extract total RNA. And the PrimeScriptTM Reagent Kit was used for reverse transcription. Quantitative polymerase chain reaction (qPCR) was performed using SYBR Green (Takara) according to the instruction of manufacture. Primers were synthesized by Sangon Biotech (China), and the sequences were listed Table 1.

\subsection{Alcian blue staining}

The ECM deposit was also determined by the Alcian blue staining. Briefly, after differentiation, cells were washed with PBS, then fixed with $4 \%$ paraformaldehyde for $15 \mathrm{~min}$. The cells were stained using Alcian blue solution for $30 \mathrm{~min}$, and washed twice with PBS before observation under microscope.

\subsection{Cellular ROS level detection}

The cellular ROS production of ADSC was detected using 2', 7'-dichlorofluorescein diacetates (DCFH-DA, Sigma-Aldrich) as previously reported[27]. Cells were washed with PBS after treatment, then the DCFH-DA was loaded at a concentration of $20 \mathrm{mmol} / \mathrm{L}$ in DMEM medium for $30 \mathrm{~min}$, and the cells were washed thrice with PBS. The fluorescent image was taken with the fluorescence microscope.

\subsection{Statistical analysis}

Results are expressed as the mean \pm standard deviation for at least three independent experiments. Data were analyzed using one-way analysis of variance (ANOVA) followed by a Tukey's post-hoc test for 
multiple comparisons (SPSS 20). A value of $\mathrm{P}<0.05$ was considered to indicate statistical significance.

\section{Results}

\subsection{Cellular toxicity of $\mathrm{Li}$}

About $40 \%$ cells were found dead after two-day treatment with $20 \mathrm{mmol} / \mathrm{L} \mathrm{LiCl}$, thus lower concentration was applied in subsequent experiments. The cellular viability was determined using Trypan Blue staining reagent. The result indicated no significant alteration on the live cell ratio after preconditioning (the data did not show). Then the cell death was also determined using the LDH assay. And the result showed similar LDH level among the groups with $0,1,4,10 \mathrm{mmol} / \mathrm{L} \mathrm{LiCl}$ (Data provided in Figure 3b). The cell morphology was also monitored, with similar cell shape between each groups after preconditioning (Figure 1). These data indicated the low cellular toxicity of LiCl to ADSC when the concentration was under $10 \mathrm{mmol} / \mathrm{L}$.

\subsection{Preconditioning of $\mathrm{LiCl}$ promotes the proliferation of ADSC}

Then, the cellular proliferation capacity was assessed by cell number counting and the Ki67 level detection after the preconditioning of $\mathrm{LiCl}$. The content of Ki67 was found increased after preconditioning by immunofluorescent staining (Figure $2 \mathrm{a}-\mathrm{b})$. And the medium group $(4 \mathrm{mmol} / \mathrm{L})$ resulted in a highest promotion $(P<0.0001)$ of $\mathrm{Ki} 67$, while higher concentration $(10 \mathrm{mmol} / \mathrm{L})$ showed a slightly increase compared to control $(P<0.05)$, while a significant inhibition compared to the low $(1 \mathrm{mmol} / \mathrm{L}, P<0.001)$ and the medium group $(P<0.0001)$.

The CCK8 kit was used to monitor the relative cell number. All preconditioned groups showed equivalent cell number with control (Figure 2c). While the preconditioned groups were found an enhanced proliferation capacity than the control after the preconditioning (Figure $2 \mathrm{~d}$ ), especially the $1 \mathrm{mmol} / \mathrm{L}$ group $(P<0.001)$. These results indicated a boost on the proliferation ability of ADSC by the preconditioning with a low concentration of $\mathrm{LiCl}$.

\subsection{Preconditioning of LiCl enhances the NP-like cell differentiation}

In addition to the proliferation ability, the NP-like cell differentiation potency was further evaluate to determine the influence of preconditioning with $\mathrm{LiCl}$. Cells were transplanted to NP cell differentiation medium after preconditioning. The mRNA level of major NP cell markers was assessed, including Col II, Aggrecan (ACAN) and SOX9. The result showed no significant changes on the mRNA level after the preconditioning compared to control (the result did not show). Notably, the level of these markers were found significantly increased in preconditioned groups than the control after a subsequent NP cell differentiation for two weeks, especially the high group (10 mmol/L). (Figure 3a)

To verify the results, the protein level of these markers were also detected, which was consistent with the mRNA expression pattern. (Figure 3b-c) Specifically, the content of ACAN and SOX9 were higher in the 10 $\mathrm{mmol} / \mathrm{L}$ group than other groups. The expression of Col II $(P<0.0001)$ and $\mathrm{Krt19}(P<0.001)$ were found 
increased in the $4 \mathrm{mmol} / \mathrm{L}$ group and the $10 \mathrm{mmol} / \mathrm{L}$ group, when compared to the control. These results suggested that the preconditioning could effectively boost the NP-like cell induction efficacy of ADSC, compared to naïve ADSC.

\subsection{Preconditioning of LiCl promotes cellular adaptation of ADSC to degenerative IVD-like condition}

The above data suggests that the preconditioning of $\mathrm{LiCl}$ can boost the proliferation ability and the NPlike cell-induction efficacy of ADSC in normal culture condition. While the hostile microenvironment in degenerated IVD is one of the major obstacles for ADSC functioning in vivo.

Given the effect of preconditioning on the cellular adaptation to degenerative IVD-like condition is still unknown, the treated cells were then challenged with the degenerative IVD-like condition, characterized by hyperosmotic pressure, acidic and a lower nutrition. The control group showed a sharp decrease of cell number, while those preconditioned groups did not. The result of CCK8 showed an over $64 \%$ cell loss in the control group, and with about $10 \%, 12 \%$, and $13 \%$ more cell survived in preconditioned groups, respectively. (Figure 4a) In addition, the cell death was confirmed using the LDH assay, which was consistent with the result of CCK8, suggesting a reduced cell death in all three preconditioned groups in degenerative IVD-like condition $(P<0.0001)$. (Figure $4 \mathrm{~b})$

Besides, the preconditioned ADSCs were cultured in NP cell induction medium, and challenged by a degenerative IVD-like condition. After two weeks, the ECM deposit was detected by Alcian blue staining. As a result, the preconditioned ADSCs exhibited a higher ECM synthesis capacity than control.(Figure 5) These results suggested an enhanced adaptation of ADSC to the degenerative IVD-like condition after preconditioning with $\mathrm{LiCl}$, with a reduced cell death and enhanced ECM synthesis ability.

\subsection{The effects of preconditioning depends on the increased cellular ROS}

The cellular ROS level was monitored, and the results showed a significantly increased ROS level in ADSC after the preconditioning of $\mathrm{LiCl}$ of $4-20 \mathrm{mmol} / \mathrm{L}$ (Figure 6a-b). To investigate the relationship between the elevated cellular ROS with the promotion of the cellular survival and the ECM deposits. ADSC microspheres were prepared and preconditioned with $\mathrm{LiCl}(10 \mathrm{mmol} / \mathrm{L})$, with (APO+) or without APO (APO-), before NP induction. The cell number was similar between the preconditioned groups. While the APO+ LiCl-preconditioned group exhibited more poor survival ability in degenerated IVD-like condition than the APO- LiCl-preconditioned group. (Figure 7a) The result indicated the APO attenuated the promotion on the cellular survival by LiCl-preconditioning.

The ECM deposits with or without APO preconditioning was also assessed after NP-induction in degenerated IVD-like condition. The APO+ LiCl-preconditioned group was found with less ECM deposits than the APO- group, as revealed by the weaker staining intensity of Alcian blue and the immunofluorescent intensity of aggrecan. (Figure 7b-d) Taken together, these data suggested the promotion on the cellular survival and ECM deposits in IVD-condition were dependent on the elevation of cellular ROS during LiCl-preconditioning. 


\section{Discussion}

The cellular adaptation to a stressed host condition is essential for a successful therapy. NP cells have been found with superior tolerance to the IVD condition, including the survival and ECM synthesis ability, rather than naïve MSC. In this study, we investigated the influences of the preconditioning with $\mathrm{LiCl}$ on the cellular behavior of ADSC under normal culture condition, and the adaptation of the preconditioned ADSC to a degenerative IVD-like condition via a series of experiments. And the results suggested that the preconditioning of $\mathrm{LiCl}$ boost the proliferation ability, and promoted the cellular adaptation of ADSC to the degenerative IVD-like condition, which reduced the cell death effectively and benefited the ECM deposit of ADSC in vitro. What is more, these effects were found closely related to the elevated cellular ROS during $\mathrm{LiCl}$-preconditioning. The application of ROS scavenger during preconditioning significantly attenuated the promotion effects on the cellular adaptation in IVD-condition.

The tissue microenvironment is composed of the biological condition, the physicomechanical and chemical condition, which affect almost every cellular activity via affecting transcriptional processes or major metabolic processes et.al. Accordingly, various strategies have been built up to regulate cellular behaviors with biological factors, such as cytokines, or to change the physicomechanical property, or to change the content of specific components in milieus.[28-30] Compared to biological methods, the treatment using physicomechanical or inorganic elements is much easier to deliver and maintain, since the modulatory efficacy is believed to turn out more stable. For example, the iron balance theory has been widely applied in anti-cancer therapy by fascinating ferroptosis of cancer cells.[31, 32] Selenium is also found essential for the synthesis of selenoprotein GPX4, which is dispensable for normal embryogenesis. [33] Lithium has been used to treat manic depression for over 100 years. Besides, lithium has also been found to paradoxically reduce lymphocyte production, but enhance their function. [34, 35] Recent studies have also identified that the promotion of cellular function of MSC occurs after preconditioning with $\mathrm{LiCl}$, which is also observed in this study, suggesting the promisingly therapeutic role in cell based treatment. $[17,18]$ The most important molecular mechanism of lithium is the mediatory action on GSK3, which could in turn phosphorylate the transcription factors to turn on the genes related to the cell growth, differentiation, inflammation et.al, such as the Wnt/ $\beta$-catenin, Myc, and the NF-kB.[36-38]

In this study, the influence of the preconditioning on cell proliferation is comparable in different groups (1$10 \mathrm{mmol} / \mathrm{L}$ ). According to the previous study, the favorable effect of lithium on the proliferation and differentiation of MSC are dose dependent.[39] Satija et al.[40] concluded the promotion on cell proliferation occurred when the concentration was less than $5 \mathrm{mmol} / \mathrm{L}$. It was also supported by de Boer et al. that lower concentration or low activity of Wnt pathway caused the proliferation of uncommitted MSC.[41] Our data is partial consistent with these findings that the cells treated with $4 \mathrm{mmol} / \mathrm{L} \mathrm{LiCl}$ exhibited the highest proliferation rate in normal or degenerative condition, and the $10 \mathrm{mmol} / \mathrm{L} \mathrm{LiCl}$ exerts weaker effect. On the other hand, the expression of NP cell markers were higher in $10 \mathrm{mmol} / \mathrm{L}$ group than the $4 \mathrm{mmol} / \mathrm{L}$ group. Therefore, we hypothesized that a higher concentration could result in a higher population of committed MSC or primed MSC, which could be further identified, for example by characterizing the metabolic flux of the preconditioned MSC with untreated MSC.[42, 43] 
Besides, our data first proved that the preconditioning of lithium enhanced the adaptation of ADSC to the degenerative IVD-like condition, including a reduced cell death and an increased ECM deposit. And our results also suggested the participant of the elevated cellular ROS in the certain process during preconditioning. Previous studies has found that ROS plays important roles in cell fate decision, and that an optimal ROS is critical for nuclear reprogramming and the generation of pluripotent stem cell.[44] Consistently, the addition of antioxidant (APO) in this study attenuated the enhancement on the cellular adaptation to harsh condition, which was considered dependent on the differentiation efficacy of ADSC in this study.

Besides, the preconditioning with $\mathrm{LiCl}$ has also been reported with strong protection to MSC against apoptosis by upregulating the gene expression of Naip1, Erc1 and Faim2.[18] In addition to the antiapoptosis gene, the lithium activates Akt-1, which is a critical protein kinase that modulate apoptotic pathway.[34] Both mechanisms may be included, against the stressed degenerative condition. In regard to the enhanced the ECM deposit of the preconditioned ADSC in degenerative IVD-like condition, the mechanism could be complex. In addition to the enhanced cell survival and a more primed MSC population as mentioned above, the influence of lithium preconditioning on the ECM catabolism requires further investigation. There are some limitations in this preliminary study, especially the lack of data from in vivo test. Further study is intended to uncover the interaction between preconditioning with lithium and the cellular adaptation, and to test its therapeutic effects in vivo.

\section{Conclusion}

In this study, we found the positive influences of preconditioning with lithium to ADSC, including the proliferation and NP-like cell differentiation efficacy under normal condition, and the cell adaptation in a hostile degenerative IVD-like condition, with an reduced cell death and enhanced ECM deposit. And these influences were closely related to the elevated ROS level in ADSC. This novel inorganic method of LiClpreconditioning exerts great application potential by boosting the ADSC activity for the IVD regeneration.

\section{Abbreviations}

ADSC $\triangle$ Adipose-derived stem cell

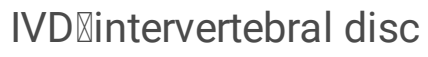

LDH囚lactate dehydrogenase

LiCl囚lithium chloride

NP囚nucleus pulpous

ECM囚extracellular matrix

ROS 『reactive oxidative species 
LBP $\triangle$ Low back pain

IVDD囚intervertebral disc degeneration

Col II囚type II collagen

BMSC凶bone marrow derived mesenchymal stem cell

GSK\glycogen synthase kinase

SD $₫$ Sprague-Dawley

FBS®fetal bovine serum

DMEM $\llbracket$ dulbecco's modified eagle medium

ITS冈Insulin-Transferrin-Selenium

BSA囚bovine serum albumin

SDS-PAGE\sodium dodecyl sulfate polyacrylamide gel electrophoresis

PVDF®polyvinylidene difluoride

ACANヌAggrecan

\section{Declarations}

\section{Availability of data and materials}

The datasets used and/or analysed during the current study are available from the corresponding author on reasonable request.

\section{Acknowledgements}

Not applicable.

\section{Funding}

This work is supported by the National Natural Science Foundation of China (no. 81603126, no. 81972514).

\section{Contributions}

$\mathrm{ZZ}$ and $\mathrm{HX}$ designed and performed the experiments, analyzed the data, and co-wrote the manuscript. RT performed the experiment. SQ, SH and QH analyzed the data and edited the manuscript. NZ designed the experiment. All authors approved the manuscript. 


\section{Ethics approval and consent to participate}

Not applicable.

\section{Consent for publication}

Not applicable.

\section{Competing interests}

The authors declare that they have no competing interests.

\section{References}

[1] F.J. Lyu, K.M. Cheung, Z. Zheng, H. Wang, D. Sakai, V.Y. Leung, IVD progenitor cells: a new horizon for understanding disc homeostasis and repair, Nat Rev Rheumatol 15(2) (2019) 102-112.

[2] L.I. Silverman, G. Dulatova, T. Tandeski, I.E. Erickson, B. Lundell, D. Toplon, T. Wolff, A. Howard, S. Chintalacharuvu, K.T. Foley, In vitro and in vivo evaluation of discogenic cells, an investigational cell therapy for disc degeneration, Spine J (2019).

[3] J. Hua, N. Shen, J. Wang, Y. Tao, F. Li, Q. Chen, X. Zhou, Small Molecule-Based Strategy Promotes Nucleus Pulposus Specific Differentiation of Adipose-Derived Mesenchymal Stem Cells, Mol Cells 42(9) (2019) 661-671.

[4] J. Clouet, M. Fusellier, A. Camus, C. Le Visage, J. Guicheux, Intervertebral disc regeneration: From cell therapy to the development of novel bioinspired endogenous repair strategies, Adv Drug Deliv Rev 146 (2019) 306-324.

[5] H. Ishiguro, T. Kaito, S. Yarimitsu, K. Hashimoto, R. Okada, J. Kushioka, R. Chijimatsu, S. Takenaka, T. Makino, Y. Sakai, Y. Moriguchi, S. Otsuru, D.A. Hart, H. Fujie, N. Nakamura, H. Yoshikawa, Intervertebral disc regeneration with an adipose mesenchymal stem cell-derived tissue-engineered construct in a rat nucleotomy model, Acta Biomater 87 (2019) 118-129.

[6] H.B. Henriksson, N. Papadimitriou, D. Hingert, A. Baranto, A. Lindahl, H. Brisby, The Traceability of Mesenchymal Stromal Cells After Injection Into Degenerated Discs in Patients with Low Back Pain, Stem Cells Dev 28(17) (2019) 1203-1211.

[7] Y.C. Huang, V.Y. Leung, W.W. Lu, K.D. Luk, The effects of microenvironment in mesenchymal stem cellbased regeneration of intervertebral disc, Spine J 13(3) (2013) 352-62.

[8] S.C. Chan, B. Gantenbein-Ritter, V.Y. Leung, D. Chan, K.M. Cheung, K. Ito, Cryopreserved intervertebral disc with injected bone marrow-derived stromal cells: a feasibility study using organ culture, The spine journal : official journal of the North American Spine Society 10(6) (2010) 486-96. 
[9] H. Li, C. Liang, Y. Tao, X. Zhou, F. Li, G. Chen, Q.X. Chen, Acidic pH conditions mimicking degenerative intervertebral discs impair the survival and biological behavior of human adipose-derived mesenchymal stem cells, Exp Biol Med (Maywood) 237(7) (2012) 845-52.

[10] D. Sakai, S. Grad, Advancing the cellular and molecular therapy for intervertebral disc disease, Adv Drug Deliv Rev 84 (2015) 159-71.

[11] H. Li, J. Wang, F. Li, G. Chen, Q. Chen, The Influence of Hyperosmolarity in the Intervertebral Disc on the Proliferation and Chondrogenic Differentiation of Nucleus Pulposus-Derived Mesenchymal Stem Cells, Cells, tissues, organs 205(3) (2018) 178-188.

[12] B. Han, H.C. Wang, H. Li, Y.Q. Tao, C.Z. Liang, F.C. Li, G. Chen, Q.X. Chen, Nucleus pulposus mesenchymal stem cells in acidic conditions mimicking degenerative intervertebral discs give better performance than adipose tissue-derived mesenchymal stem cells, Cells, tissues, organs 199(5-6) (2014) 342-52.

[13] S.M. Richardson, G. Kalamegam, P.N. Pushparaj, C. Matta, A. Memic, A. Khademhosseini, R. Mobasheri, F.L. Poletti, J.A. Hoyland, A. Mobasheri, Mesenchymal stem cells in regenerative medicine: Focus on articular cartilage and intervertebral disc regeneration, Methods 99 (2016) 69-80.

[14] S.M. Richardson, J.A. Hoyland, R. Mobasheri, C. Csaki, M. Shakibaei, A. Mobasheri, Mesenchymal stem cells in regenerative medicine: opportunities and challenges for articular cartilage and intervertebral disc tissue engineering, J Cell Physiol 222(1) (2010) 23-32.

[15] L.E.B. Souza, L.R. Beckenkamp, L.M. Sobral, D.M.C. Fantacini, F.U.F. Melo, J.S. Borges, A.M. Leopoldino, S. Kashima, D.T. Covas, Pre-culture in endothelial growth medium enhances the angiogenic properties of adipose-derived stem/stromal cells, Angiogenesis 21(1) (2018) 15-22.

[16] J. Watanabe, M. Yamada, K. Niibe, M. Zhang, T. Kondo, M. Ishibashi, H. Egusa, Preconditioning of bone marrow-derived mesenchymal stem cells with $\mathrm{N}$-acetyl-L-cysteine enhances bone regeneration via reinforced resistance to oxidative stress, Biomaterials 185 (2018) 25-38.

[17] T.M. Lee, H.J. Harn, T.W. Chiou, M.H. Chuang, C.H. Chen, P.C. Lin, S.Z. Lin, Targeting the pathway of GSK-3beta/nerve growth factor to attenuate post-infarction arrhythmias by preconditioned adiposederived stem cells, Journal of molecular and cellular cardiology 104 (2017) 17-30.

[18] G.R. Linares, C.T. Chiu, L. Scheuing, Y. Leng, H.M. Liao, D. Maric, D.M. Chuang, Preconditioning mesenchymal stem cells with the mood stabilizers lithium and valproic acid enhances therapeutic efficacy in a mouse model of Huntington's disease, Experimental neurology 281 (2016) 81-92.

[19] W. Liu, T. Li, C. Yang, D. Wang, G. He, M. Cheng, Q. Wang, X. Zhang, Lithium-Incorporated Nanoporous Coating Formed by Micro Arc Oxidation (MAO) on Magnesium Alloy with Improved Corrosion Resistance, Angiogenesis and Osseointegration, Journal of biomedical nanotechnology 15(6) (2019) 1172-1184. 
[20] Y. Luo, D. Li, J. Zhao, Z. Yang, P. Kang, In vivo evaluation of porous lithium-doped hydroxyapatite scaffolds for the treatment of bone defect, Biomed Mater Eng 29(6) (2018) 699-721.

[21] D. Li, X. Xie, Z. Yang, C. Wang, Z. Wei, P. Kang, Enhanced bone defect repairing effects in glucocorticoid-induced osteonecrosis of the femoral head using a porous nano-lithium-

hydroxyapatite/gelatin microsphere/erythropoietin composite scaffold, Biomaterials science 6(3) (2018) 519-537.

[22] Z. Zhu, J. Yin, J. Guan, B. Hu, X. Niu, D. Jin, Y. Wang, C. Zhang, Lithium stimulates human bone marrow derived mesenchymal stem cell proliferation through GSK-3beta-dependent beta-catenin/Wnt pathway activation, FEBS J 281(23) (2014) 5371-89.

[23] H. Kazemi, A. Noori-Zadeh, S. Darabi, F. Rajaei, Lithium prevents cell apoptosis through autophagy induction, Bratisl Lek Listy 119(4) (2018) 234-239.

[24] C. Liang, H. Li, Y. Tao, X. Zhou, F. Li, G. Chen, Q. Chen, Responses of human adipose-derived mesenchymal stem cells to chemical microenvironment of the intervertebral disc, Journal of translational medicine 10 (2012) 49.

[25] K. Wuertz, K. Godburn, C. Neidlinger-Wilke, J. Urban, J.C. latridis, Behavior of mesenchymal stem cells in the chemical microenvironment of the intervertebral disc, Spine 33(17) (2008) 1843-9.

[26] J. Wang, Y. Tao, X. Zhou, H. Li, C. Liang, F. Li, Q.X. Chen, The potential of chondrogenic predifferentiation of adipose-derived mesenchymal stem cells for regeneration in harsh nucleus pulposus microenvironment, Experimental biology and medicine 241(18) (2016) 2104-2111.

[27] A.K. Gaharwar, S.M. Mihaila, A. Swami, A. Patel, S. Sant, R.L. Reis, A.P. Marques, M.E. Gomes, A. Khademhosseini, Bioactive silicate nanoplatelets for osteogenic differentiation of human mesenchymal stem cells, Advanced materials 25(24) (2013) 3329-36.

[28] M. Segel, B. Neumann, M.F.E. Hill, I.P. Weber, C. Viscomi, C. Zhao, A. Young, C.C. Agley, A.J. Thompson, G.A. Gonzalez, A. Sharma, S. Holmqvist, D.H. Rowitch, K. Franze, R.J.M. Franklin, K.J. Chalut, Niche stiffness underlies the ageing of central nervous system progenitor cells, Nature 573(7772) (2019) 130-134.

[29] K. Johnson, S. Zhu, M.S. Tremblay, J.N. Payette, J. Wang, L.C. Bouchez, S. Meeusen, A. Althage, C.Y. Cho, X. Wu, P.G. Schultz, A stem cell-based approach to cartilage repair, Science 336(6082) (2012) 717-21.

[30] Y.A. Sulistio, H.K. Lee, S.J. Jung, K. Heese, Interleukin-6-Mediated Induced Pluripotent Stem Cell (iPSC)-Derived Neural Differentiation, Mol Neurobiol 55(4) (2018) 3513-3522.

[31] J.P. Friedmann Angeli, D.V. Krysko, M. Conrad, Ferroptosis at the crossroads of cancer-acquired drug resistance and immune evasion, Nature reviews. Cancer 19(7) (2019) 405-414. 
[32] M.P. Murphy, Metabolic control of ferroptosis in cancer, Nature cell biology 20(10) (2018) 1104-1105.

[33] I. Ingold, C. Berndt, S. Schmitt, S. Doll, G. Poschmann, K. Buday, A. Roveri, X. Peng, F. Porto Freitas, T. Seibt, L. Mehr, M. Aichler, A. Walch, D. Lamp, M. Jastroch, S. Miyamoto, W. Wurst, F. Ursini, E.S.J. Arner, N. Fradejas-Villar, U. Schweizer, H. Zischka, J.P. Friedmann Angeli, M. Conrad, Selenium Utilization by GPX4 Is Required to Prevent Hydroperoxide-Induced Ferroptosis, Cell 172(3) (2018) 409-422 e21.

[34] W. Young, Review of lithium effects on brain and blood, Cell transplantation 18(9) (2009) 951-75.

[35] B. Liu, Q. Wu, S. Zhang, A. Del Rosario, Lithium use and risk of fracture: a systematic review and meta-analysis of observational studies, Osteoporosis international : a journal established as result of cooperation between the European Foundation for Osteoporosis and the National Osteoporosis Foundation of the USA 30(2) (2019) 257-266.

[36] A. Hiyama, D. Sakai, F. Arai, D. Nakajima, K. Yokoyama, J. Mochida, Effects of a glycogen synthase kinase-3beta inhibitor $(\mathrm{LiCl})$ on c-myc protein in intervertebral disc cells, Journal of cellular biochemistry 112 (10) (2011) 2974-86.

[37] W.M. Raup-Konsavage, T.K. Cooper, G.S. Yochum, A Role for MYC in Lithium-Stimulated Repair of the Colonic Epithelium After DSS-Induced Damage in Mice, Digestive diseases and sciences 61(2) (2016) 410-22.

[38] M.B. Eslaminejad, N. Karimi, M. Shahhoseini, Chondrogenic differentiation of human bone marrowderived mesenchymal stem cells treated by GSK-3 inhibitors, Histochemistry and cell biology 140(6) (2013) 623-33.

[39] E. Ferensztajn-Rochowiak, J.K. Rybakowski, The effect of lithium on hematopoietic, mesenchymal and neural stem cells, Pharmacol Rep 68(2) (2016) 224-30.

[40] N.K. Satija, D. Sharma, F. Afrin, R.P. Tripathi, G. Gangenahalli, High throughput transcriptome profiling of lithium stimulated human mesenchymal stem cells reveals priming towards osteoblastic lineage, PLoS One 8(1) (2013) e55769.

[41] J. De Boer, H.J. Wang, C. Van Blitterswijk, Effects of Wnt signaling on proliferation and differentiation of human mesenchymal stem cells, Tissue Eng 10(3-4) (2004) 393-401.

[42] M.R. Showalter, B. Wancewicz, O. Fiehn, J.A. Archard, S. Clayton, J. Wagner, P. Deng, J. Halmai, K.D. Fink, G. Bauer, B. Fury, N.H. Perotti, M. Apperson, J. Butters, P. Belafsky, G. Farwell, M. Kuhn, J.A. Nolta, J.D. Anderson, Primed mesenchymal stem cells package exosomes with metabolites associated with immunomodulation, Biochemical and biophysical research communications 512(4) (2019) 729-735.

[43] E. Avigad Laron, E. Aamar, D. Enshell-Seijffers, The Mesenchymal Niche of the Hair Follicle Induces Regeneration by Releasing Primed Progenitors from Inhibitory Effects of Quiescent Stem Cells, Cell reports 24(4) (2018) 909-921 e3. 
[44] G. Zhou, S. Meng, Y.H. Li, Y.T. Ghebre, J.P. Cooke, Optimal ROS Signaling Is Critical for Nuclear Reprogramming, Cell reports 15(5) (2016) 919-925.

\section{Tables}

Table I. Primers used in quantitative PCR

\begin{tabular}{|lll|}
\hline & Primer, 5'-3' & \\
\hline Gene & Forward & Reverse \\
\hline $18 S$ & GAATTCCCAGTAAGTGCGGGTCATA & CGAGGGCCTCACTAAACCATC \\
Acan & CTAGCTGCTTAGCAGGGATAACG & GATGACCCGCAGAGTCACAAAG \\
Col II & CTGGTGGAGCAGCAAGAGC & GTGGACAGTAGACGGAGGAAAG \\
Sox 9 & AGGAAGCTGGCAGACCAGTACC & GGGTCTCTTCTCGCTCTCGTTCA \\
\hline
\end{tabular}

\section{Figures}

\section{Control}

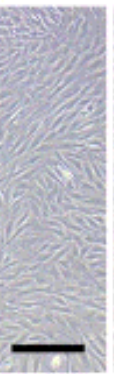

$1 \mathrm{mmol} / \mathrm{L}$

$4 \mathrm{mmol} / \mathrm{L}$

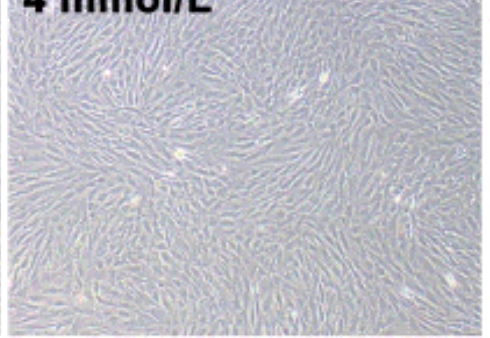

\section{$10 \mathrm{mmol} / \mathrm{L}$}

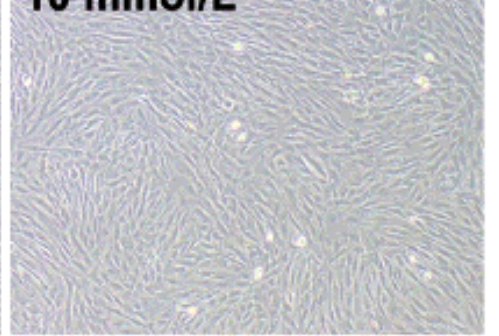

\section{Figure 1}

Morphology characterization after the preconditioning with LiCl. No obvious morphological changes observed between each groups. Scale bar $=100 \mu \mathrm{m}$.

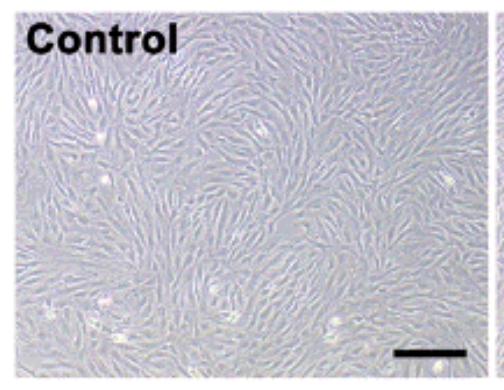

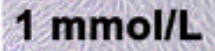

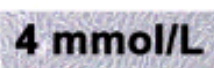

\section{$10 \mathrm{mmol} / \mathrm{L}$}

\section{Figure 1}

Morphology characterization after the preconditioning with LiCl. No obvious morphological changes observed between each groups. Scale bar $=100 \mu \mathrm{m}$. 
a
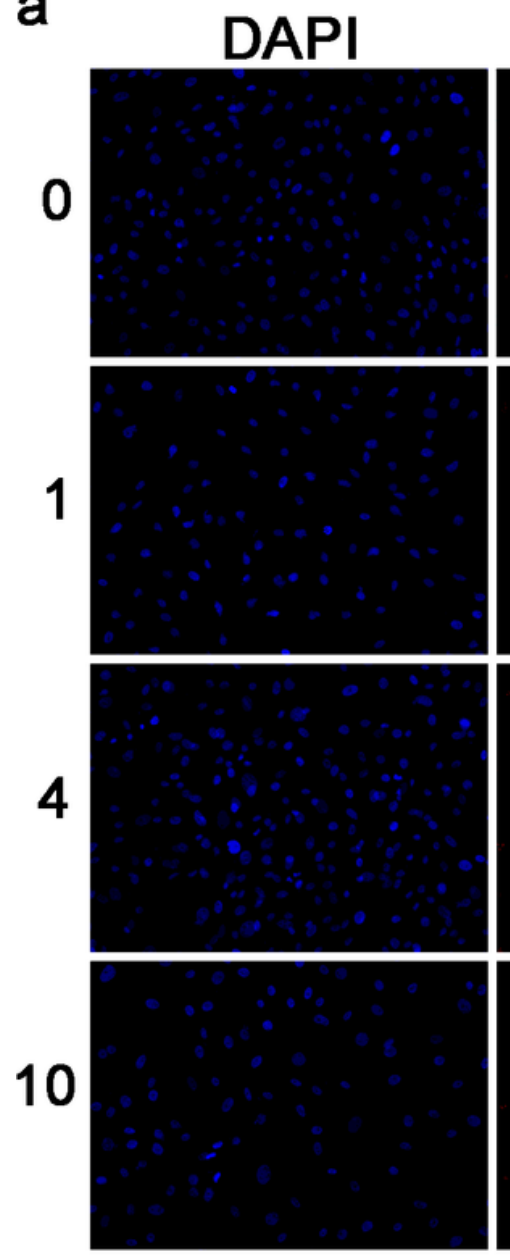

Ki67
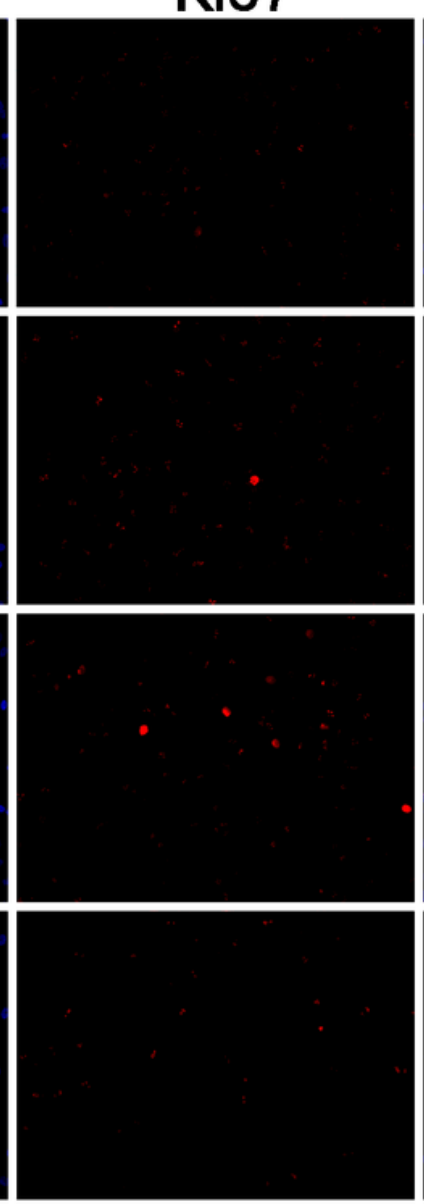

Merge
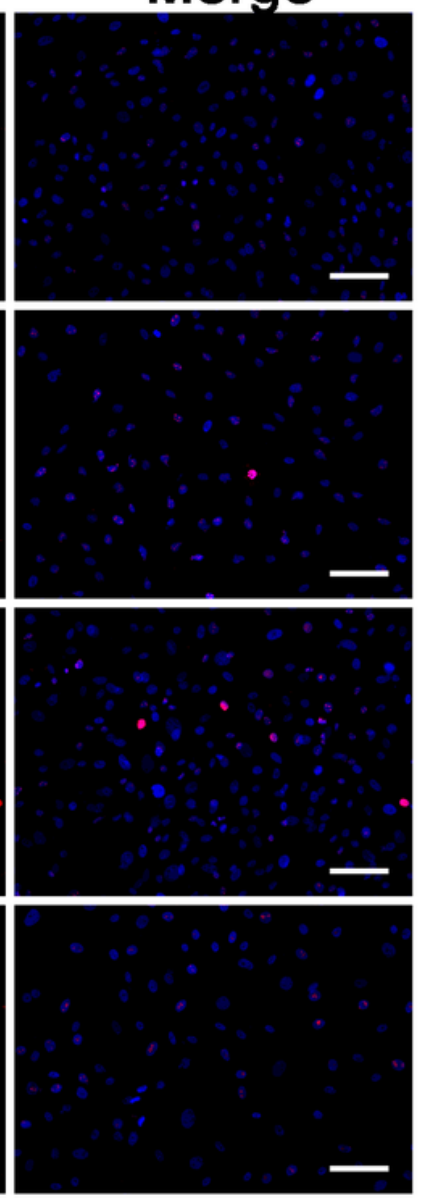

b

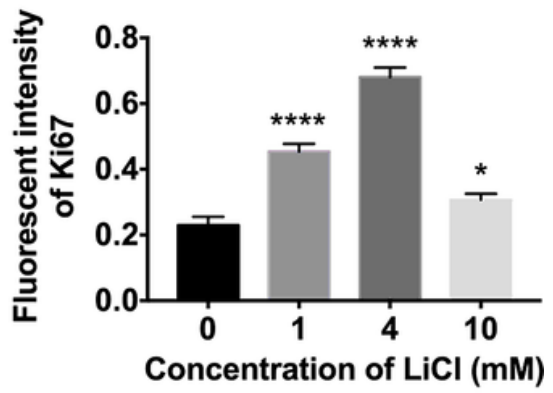

C

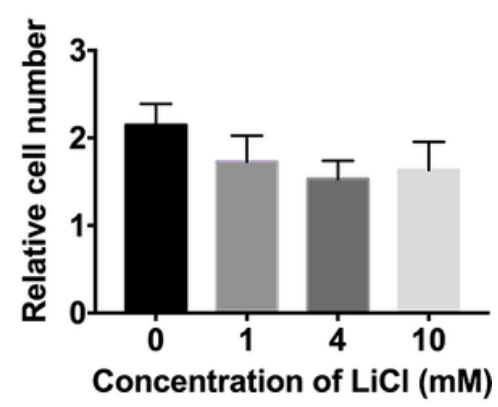

d

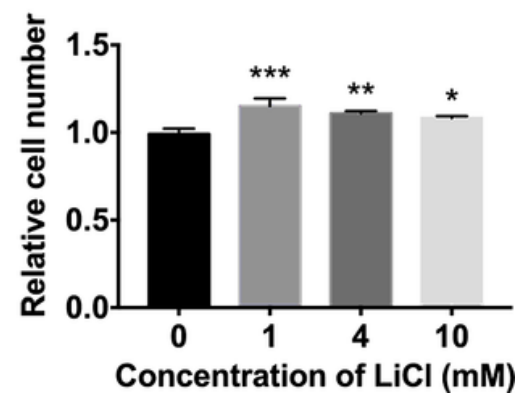

Figure 2

Preconditioning using LiCl promotes ADSC proliferation. (a) Immunofluorescent staining of Ki67 after preconditioning, scale bar $=200 \mu \mathrm{m}$; (b) Quantitative analysis of Ki67 content. (c) Relative cell number of ADSC after preconditioning, and (d) two day-post preconditioning. Error bars depict Mean \pm SD. $(\star \star \star \star P<$ $0.0001,{ }^{\star} \star * P<0.001,{ }^{*} \mathrm{P}<0.01,{ }^{*} \mathrm{P}<0.05$. NS, nonsignificant) 
a
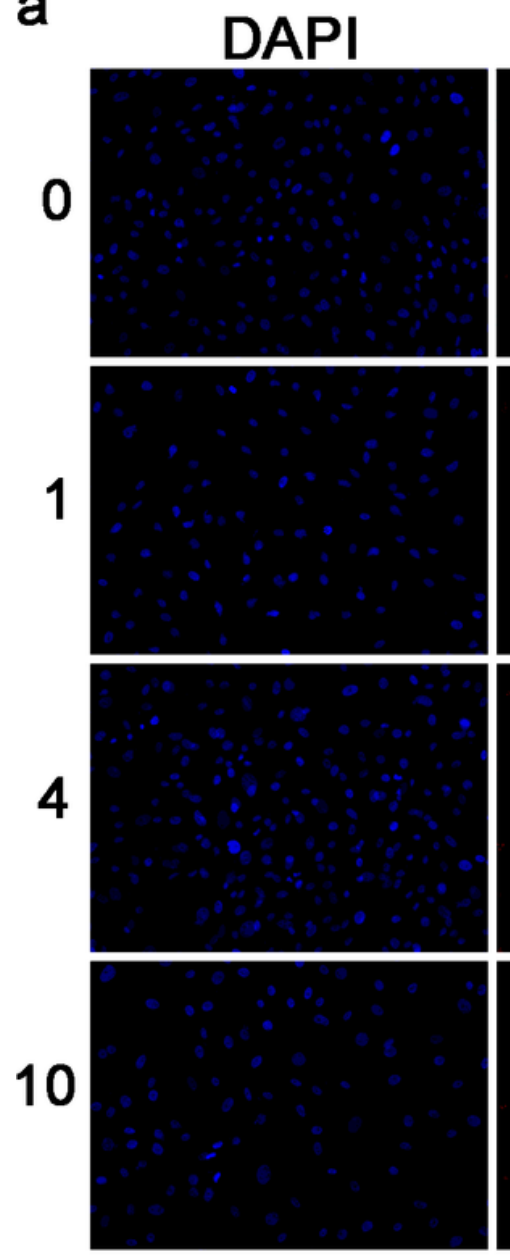

Ki67
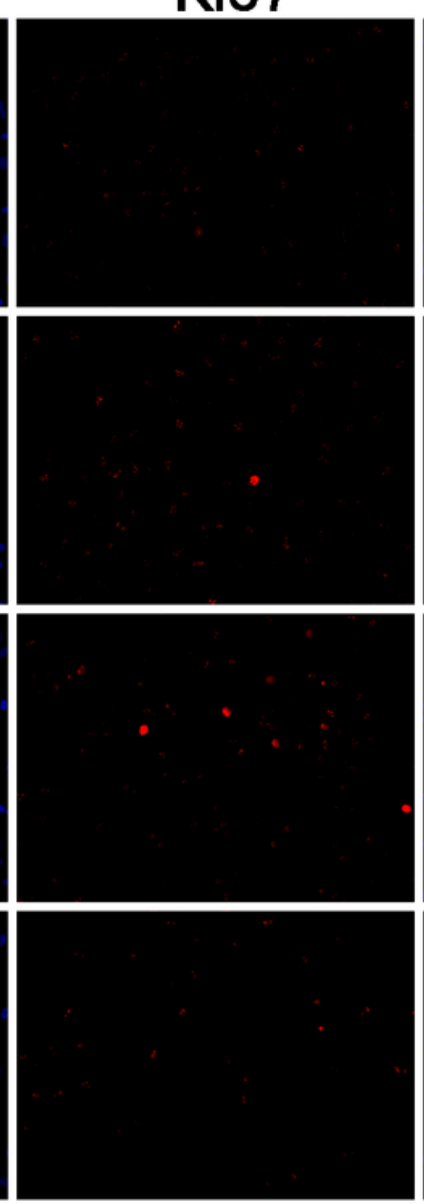

Merge
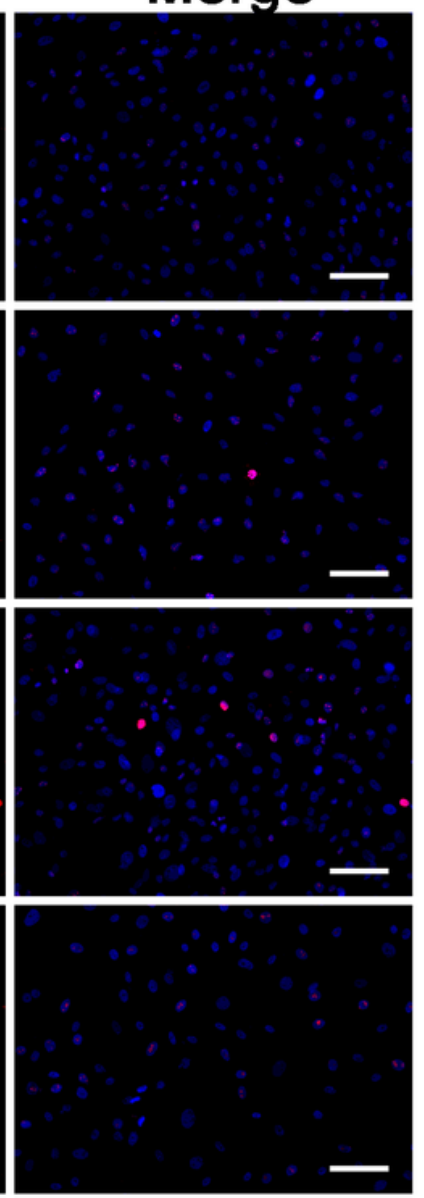

b

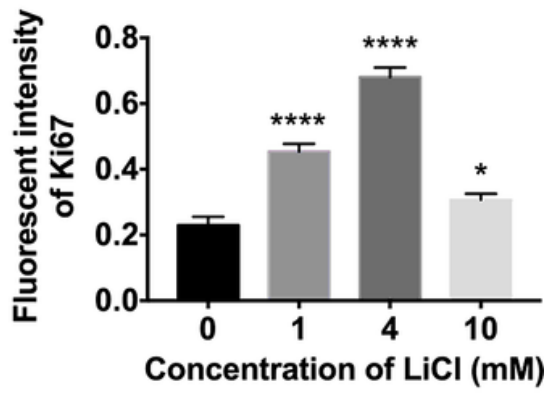

C

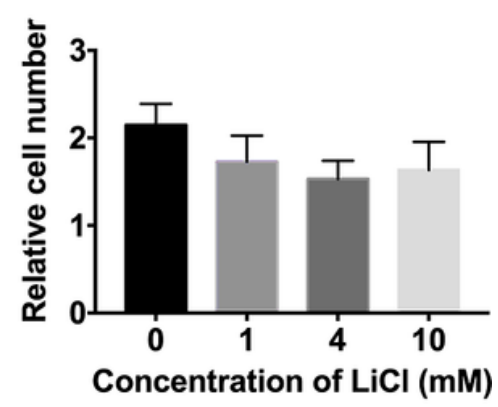

d

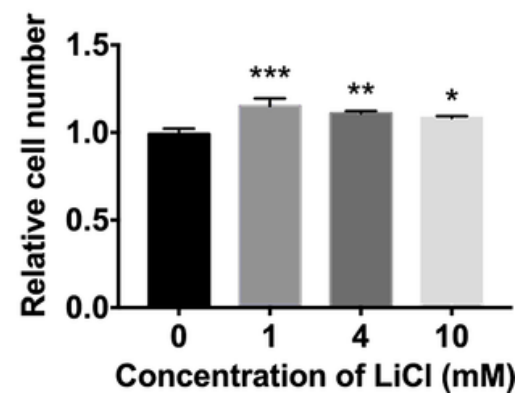

Figure 2

Preconditioning using LiCl promotes ADSC proliferation. (a) Immunofluorescent staining of Ki67 after preconditioning, scale bar $=200 \mu \mathrm{m}$; (b) Quantitative analysis of Ki67 content. (c) Relative cell number of ADSC after preconditioning, and (d) two day-post preconditioning. Error bars depict Mean \pm SD. $(\star \star \star \star P<$ $0.0001,{ }^{\star} \star * P<0.001,{ }^{*} \mathrm{P}<0.01,{ }^{*} \mathrm{P}<0.05$. NS, nonsignificant) 


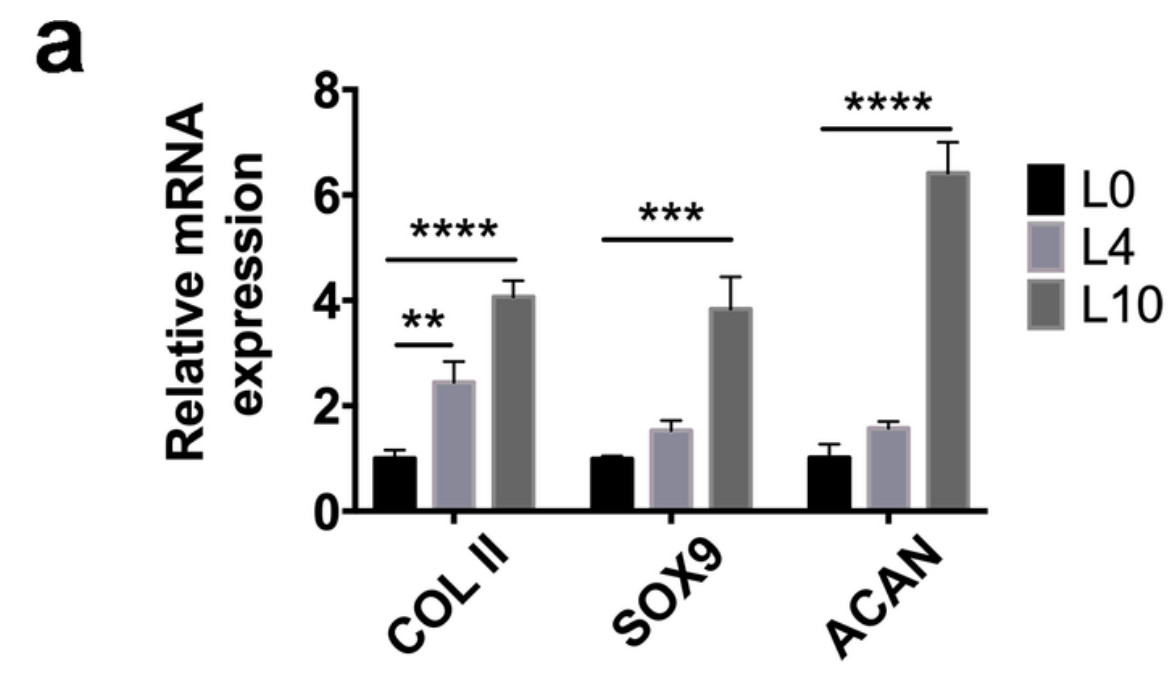

b

Lithium(mM) $\quad 0 \quad 4 \quad 10$

COL II

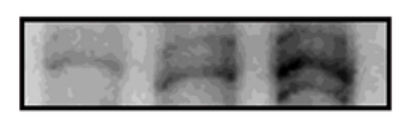

ACAN

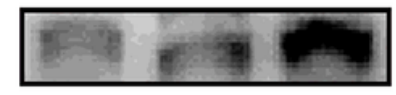

Krt 19

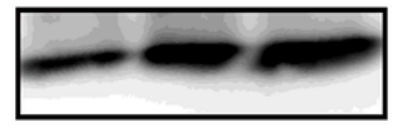

sox 9

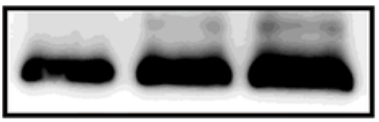

GAPDH
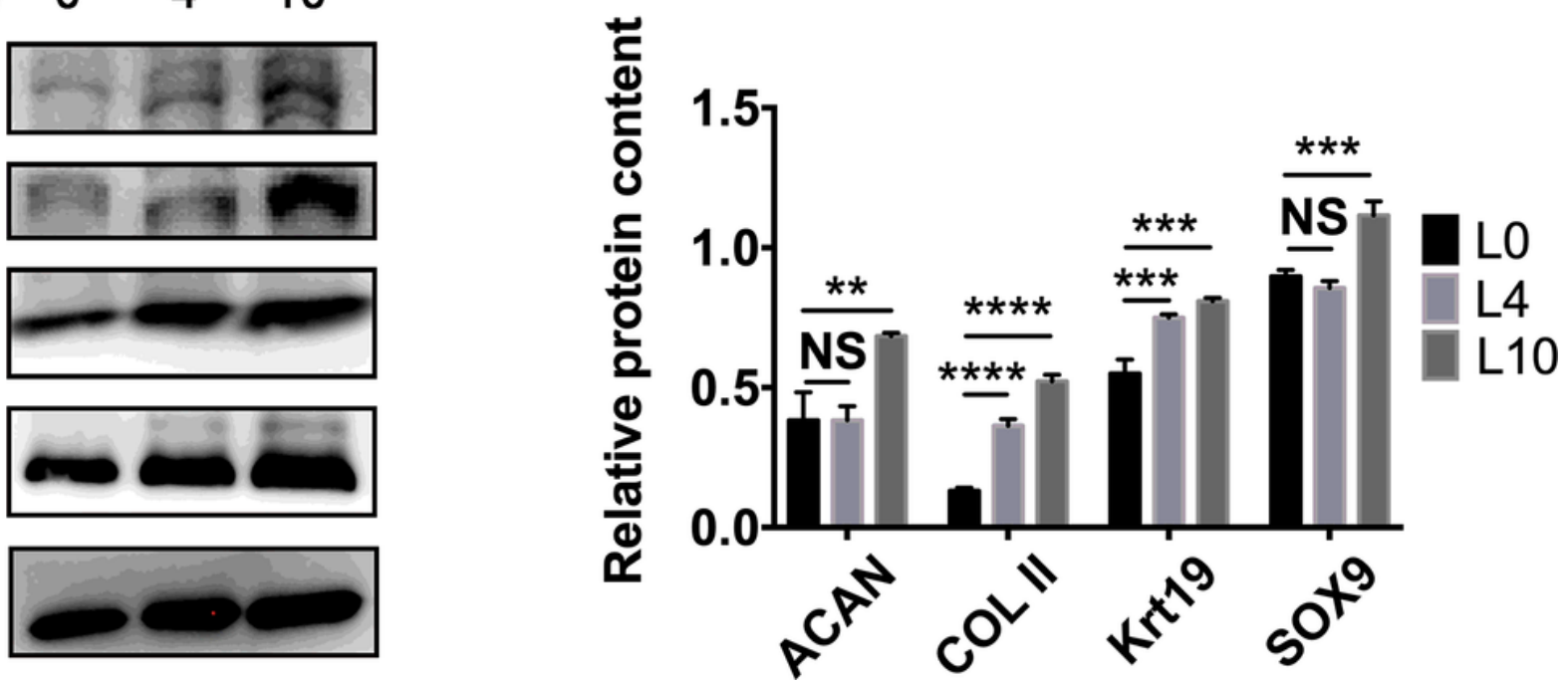

Figure 3

Preconditioning of $\mathrm{LiCl}$ promotes the NP cell phenotype differentiation efficacy. (a) Relative mRNA expression of NP cell markers after preconditioning. (b-c) Protein level of NP-cell markers after preconditioning. Error bars depict Mean $\pm S D$. $\left({ }^{\star * \star * P}<0.0001,{ }^{\star * \star} P<0.001,{ }^{\star *} P<0.01\right.$. NS, nonsignificant) 


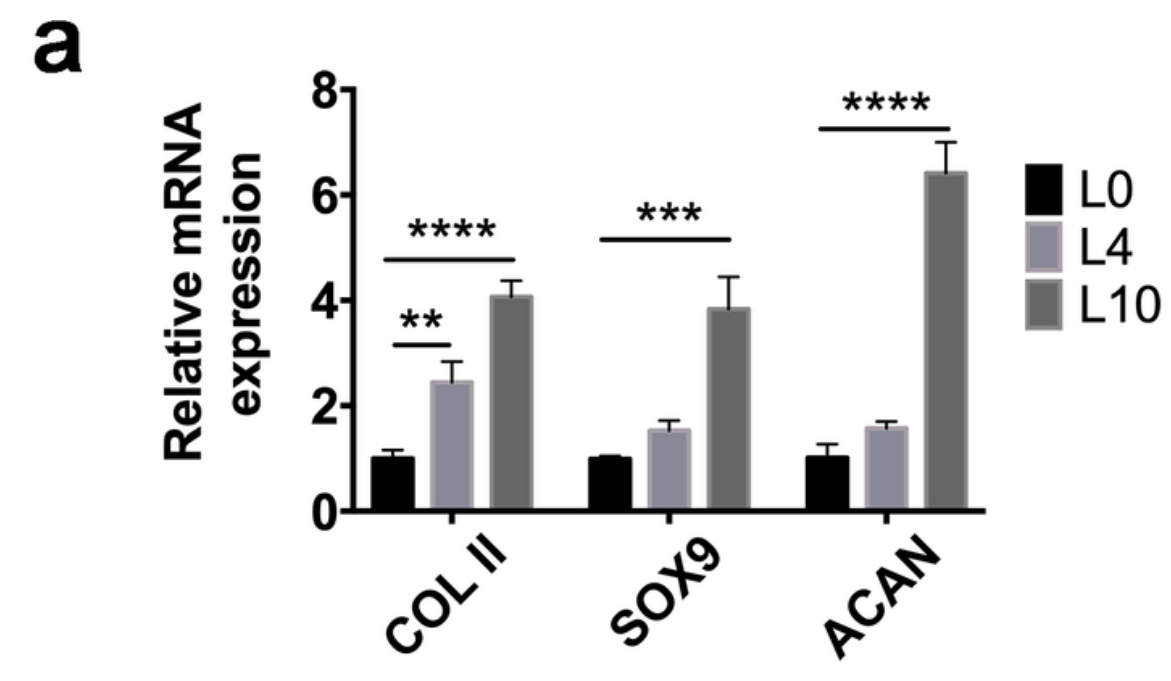

b

Lithium(mM) $\quad 0 \quad 4 \quad 10$

COL II

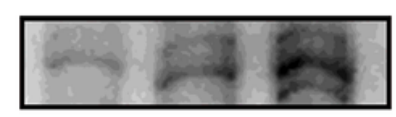

ACAN

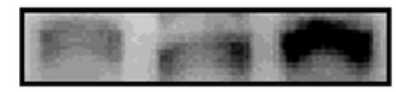

Krt 19

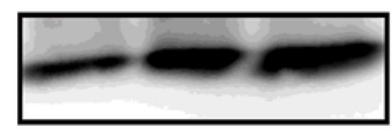

sox 9

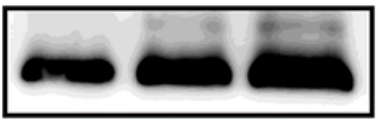

GAPDH
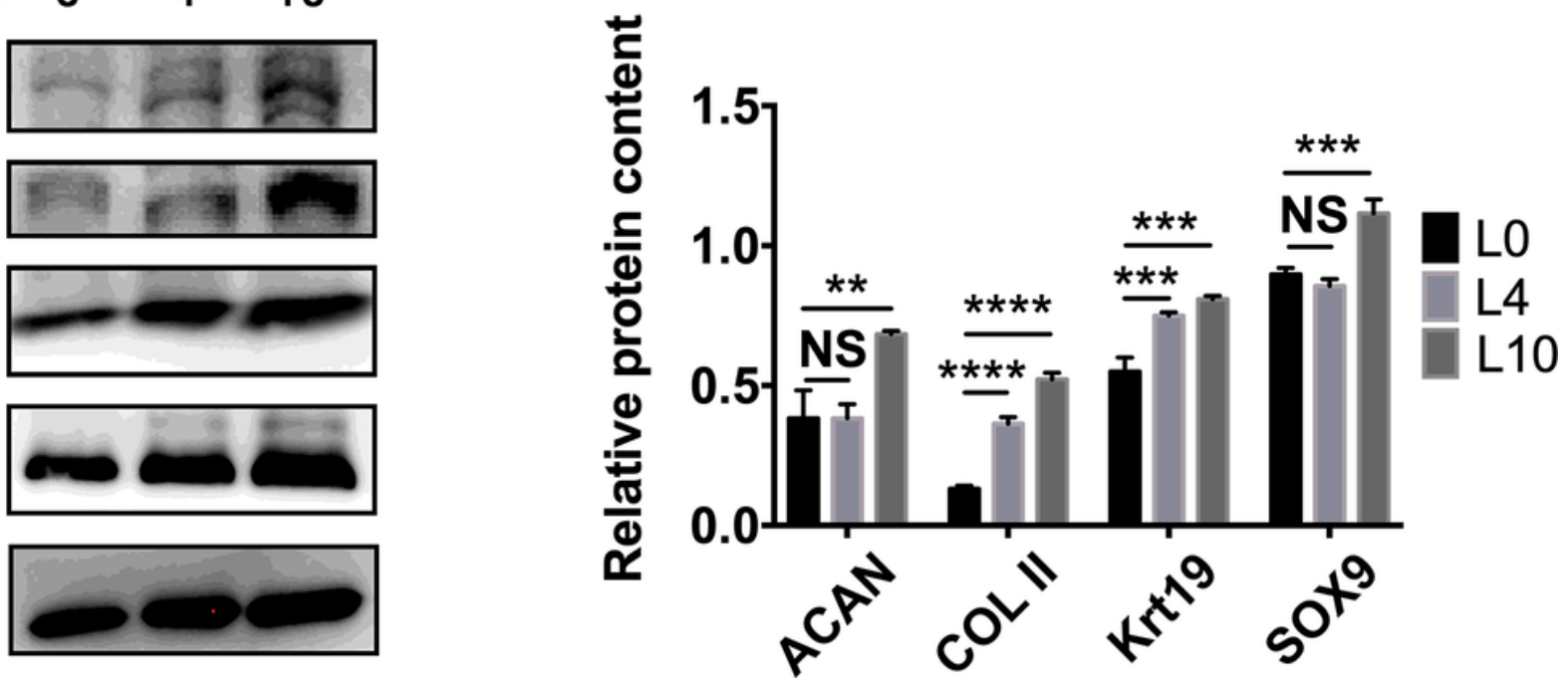

Figure 3

Preconditioning of $\mathrm{LiCl}$ promotes the NP cell phenotype differentiation efficacy. (a) Relative mRNA expression of NP cell markers after preconditioning. (b-c) Protein level of NP-cell markers after preconditioning. Error bars depict Mean $\pm S D$. $\left({ }^{\star * \star * P}<0.0001,{ }^{\star * \star} P<0.001,{ }^{\star *} P<0.01\right.$. NS, nonsignificant) 


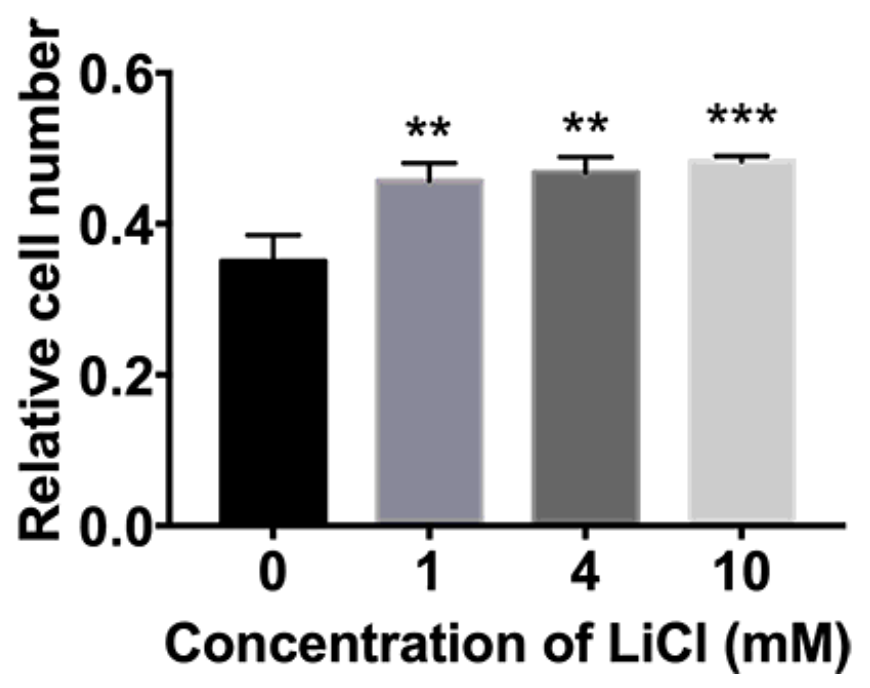

b

Figure 4

Preconditioning using $\mathrm{LiCl}$ promotes cell survival in the degenerative IVD-like condition. (a) Relative cell number at two days post-transplantation; (b) Content of LDH of ADSC in normal condition or degenerative IVD-like condition. Error bars depict Mean $\pm \mathrm{SD}$. $\left({ }^{\star * *} \mathrm{P}<0.0001\right.$, ${ }^{\star * *} \mathrm{P}<0.001,{ }^{*} \mathrm{P}<0.01$.)

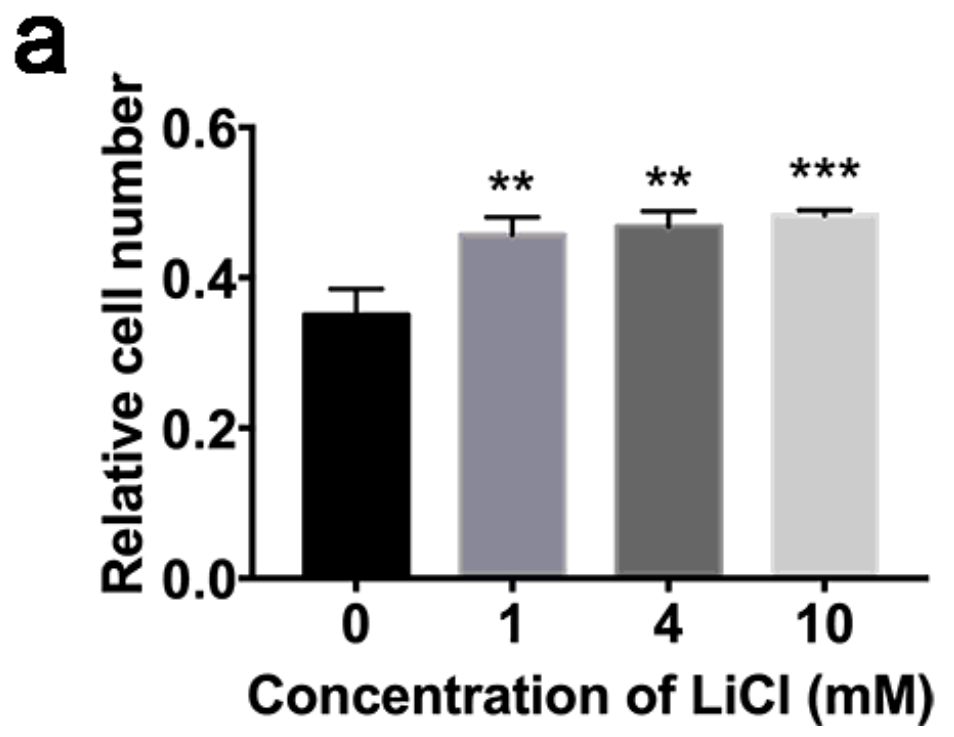

b
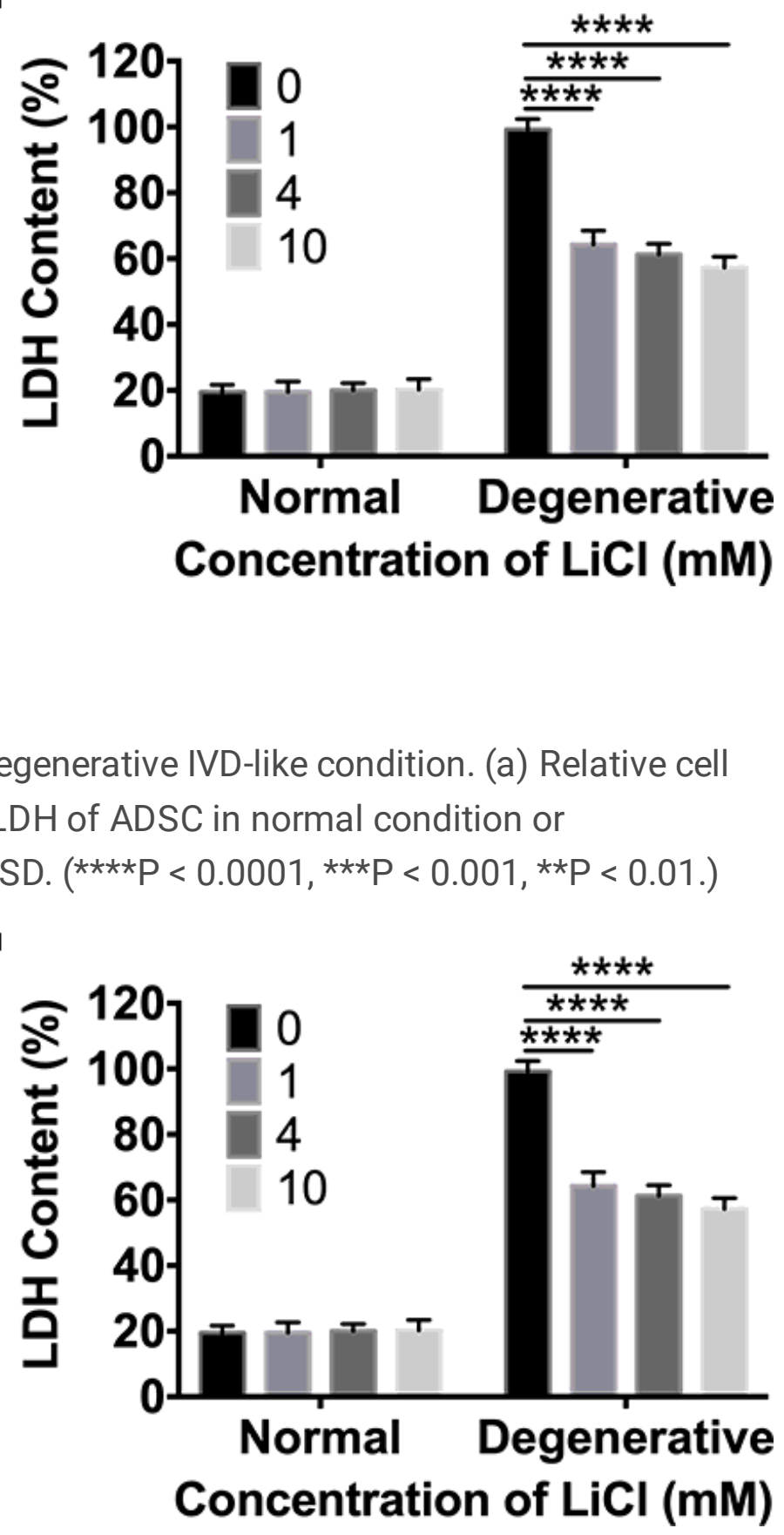

Figure 4

Preconditioning using $\mathrm{LiCl}$ promotes cell survival in the degenerative IVD-like condition. (a) Relative cell number at two days post-transplantation; (b) Content of LDH of ADSC in normal condition or degenerative IVD-like condition. Error bars depict Mean \pm SD. $\left(* \star \star * P<0.0001, * \star * P<0.001,{ }^{\star *} P<0.01\right.$. $)$ 
0

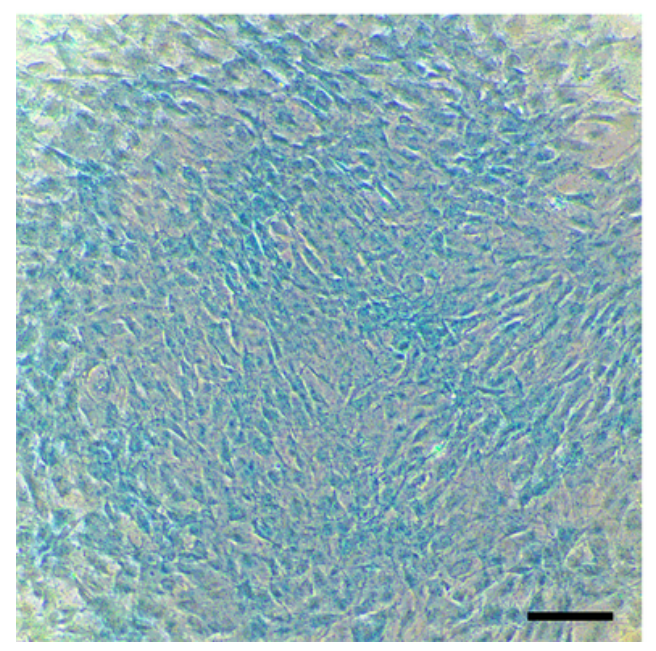

4

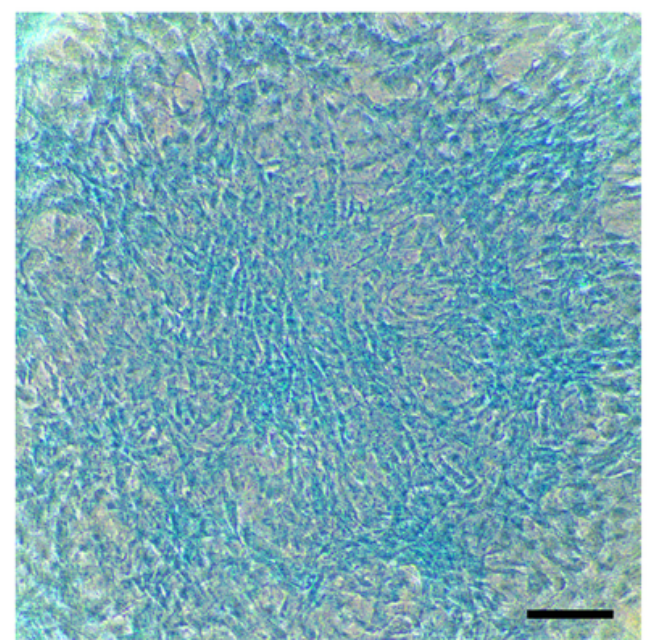

10

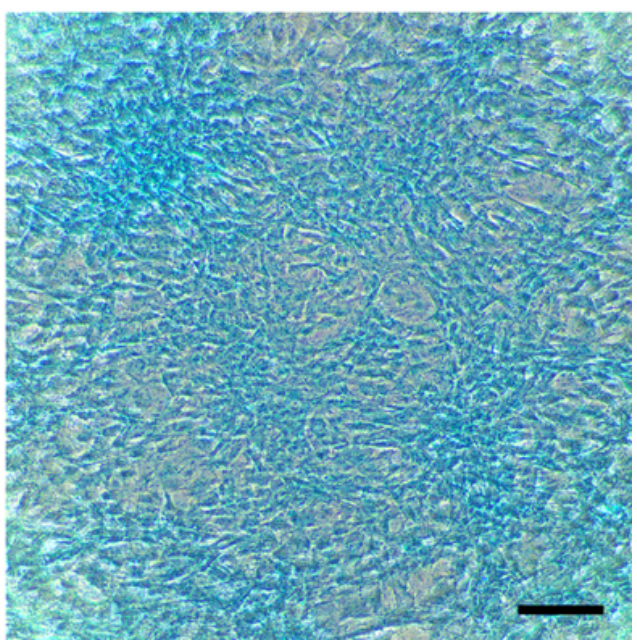

\section{Figure 5}

Preconditioning with $\mathrm{LiCl}$ mitigates the inhibitory effect on ECM deposit under the degenerative IVD-like condition. The ECM content was determined using Alcian Blue staining. Scale bar $=100 \mu \mathrm{m}$.

0

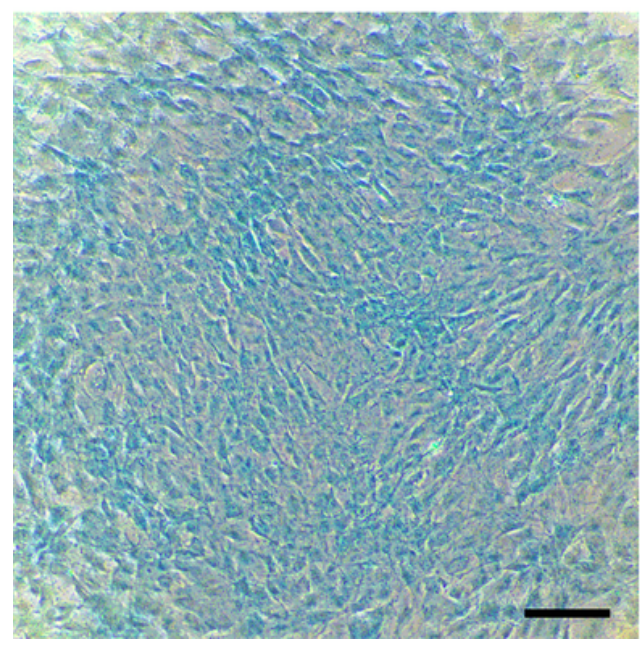

4

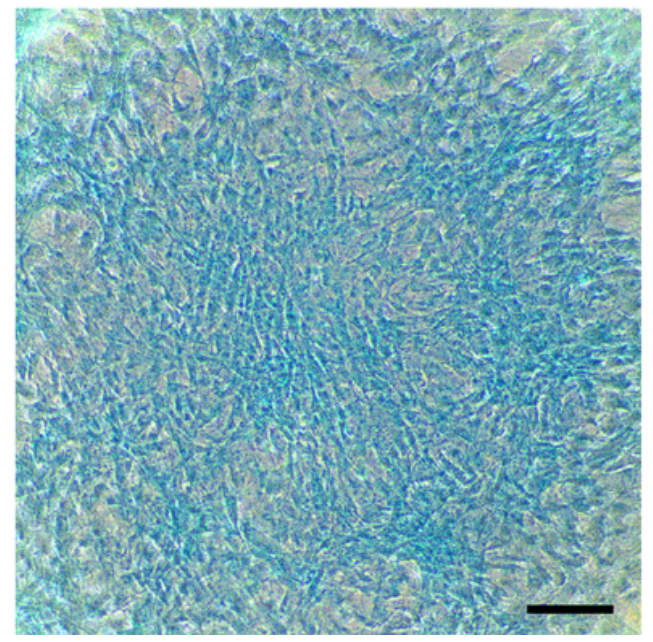

10

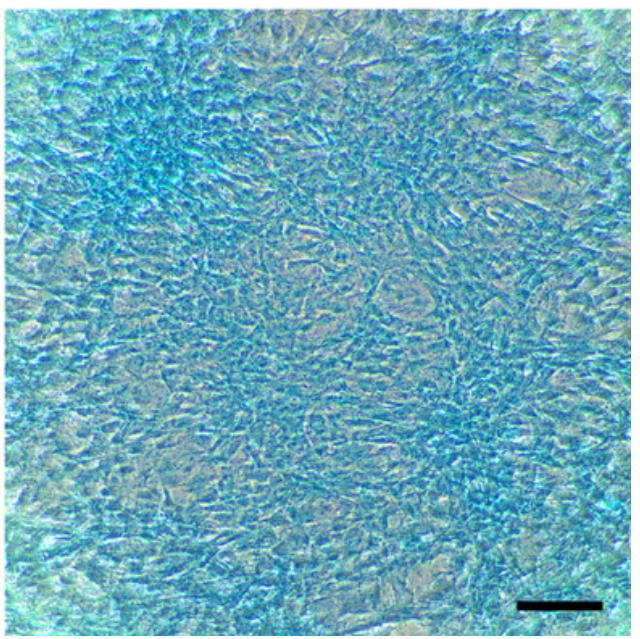

\section{Figure 5}

Preconditioning with $\mathrm{LiCl}$ mitigates the inhibitory effect on ECM deposit under the degenerative IVD-like condition. The ECM content was determined using Alcian Blue staining. Scale bar $=100 \mu \mathrm{m}$. 


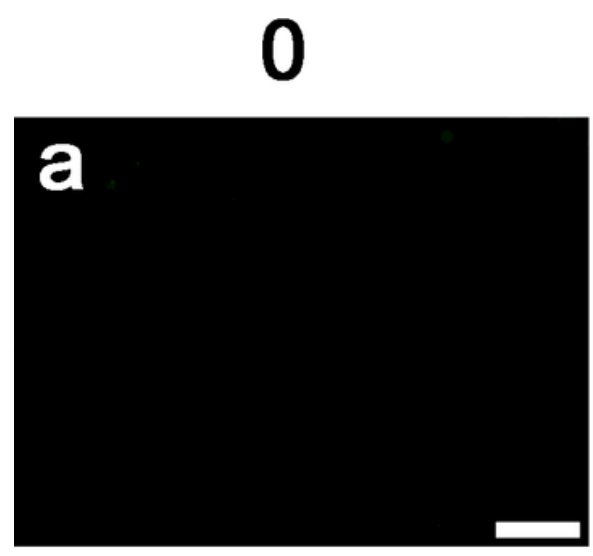

10

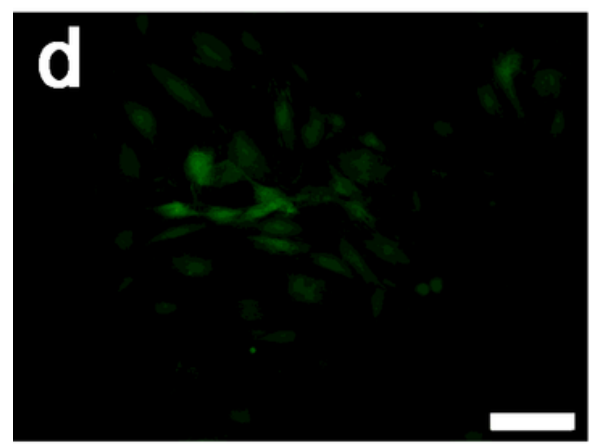

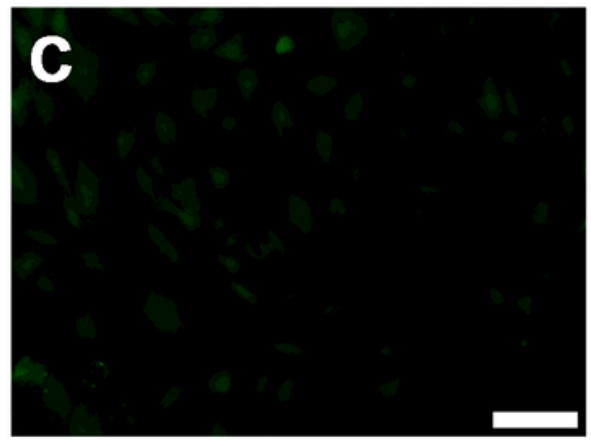
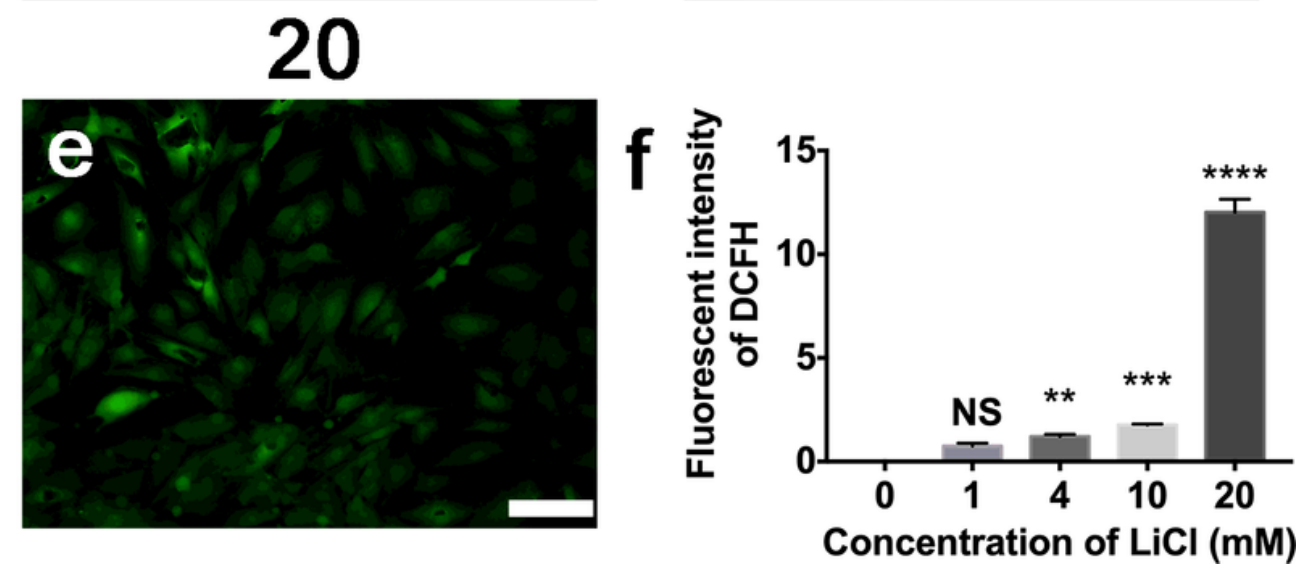

Figure 6

Preconditioning of $\mathrm{LiCl}$ increased cellular ROS level in ADSC. (a-e) The cellular ROS after preconditioning with $\mathrm{LiCl}$ was detected using DCFH-DA, scale bar $=100 \mu \mathrm{m}$. (f) Quantitative analyses of cellular ROS level. Error bars depict Mean \pm SD. ( ${ }^{\star \star \star \star} P<0.0001,{ }^{\star \star *} P<0.001,{ }^{\star *} \mathrm{P}<0.01$. NS, nonsignificant) 


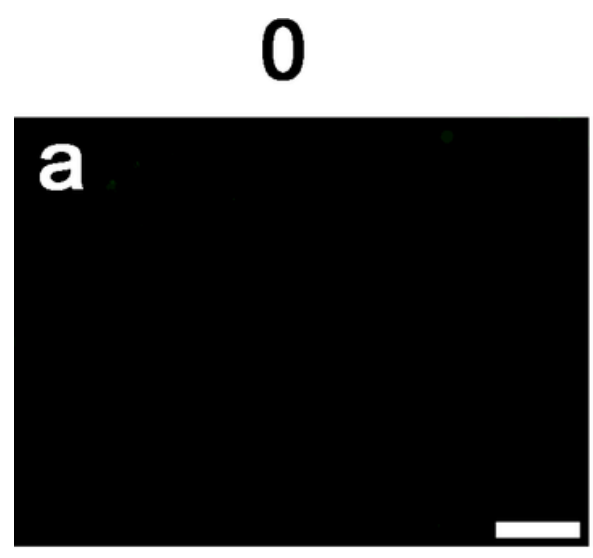

10

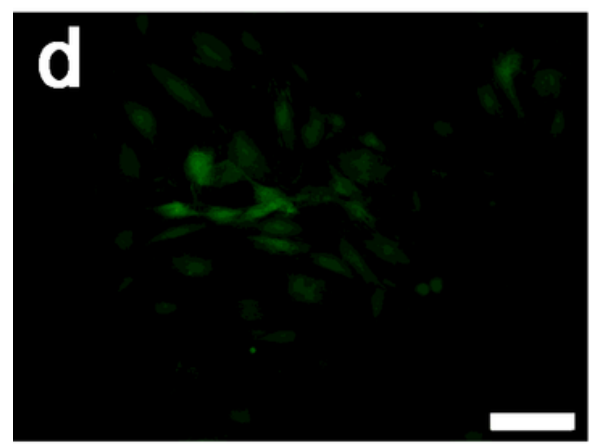

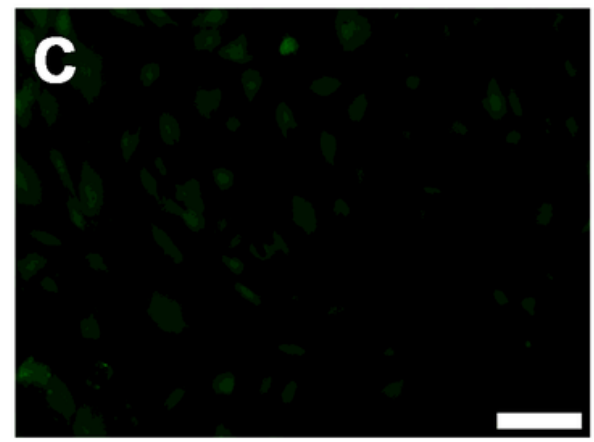
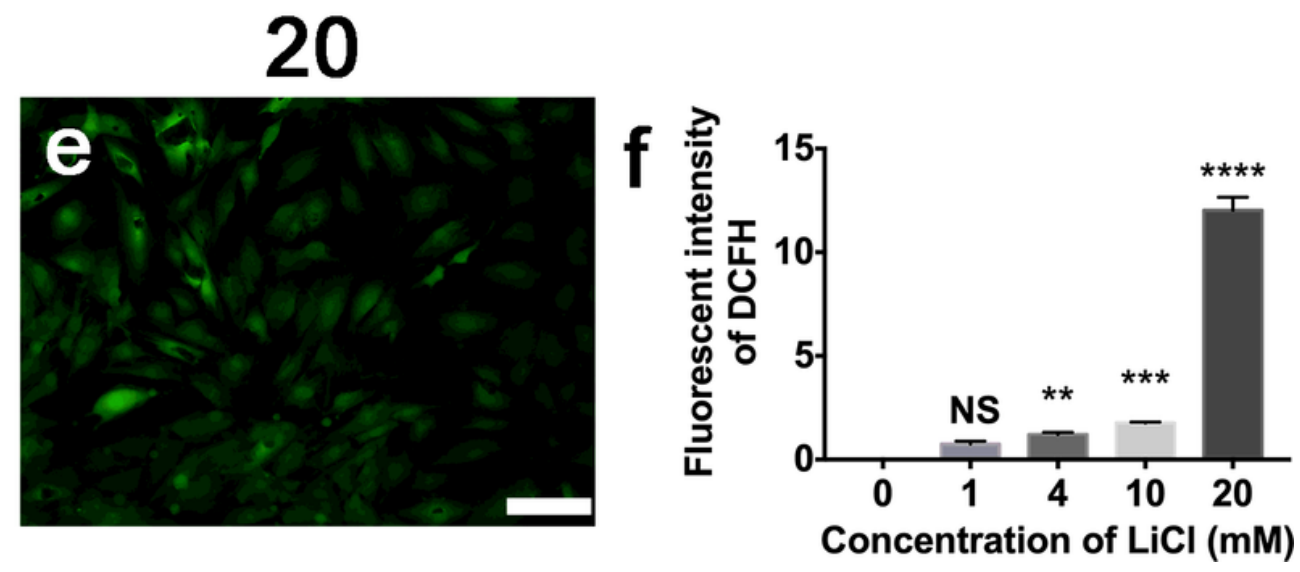

Figure 6

Preconditioning of $\mathrm{LiCl}$ increased cellular ROS level in ADSC. (a-e) The cellular ROS after preconditioning with $\mathrm{LiCl}$ was detected using DCFH-DA, scale bar $=100 \mu \mathrm{m}$. (f) Quantitative analyses of cellular ROS level. Error bars depict Mean \pm SD. ( ${ }^{\star \star \star \star} P<0.0001,{ }^{\star \star *} P<0.001,{ }^{\star *} \mathrm{P}<0.01$. NS, nonsignificant) 
a

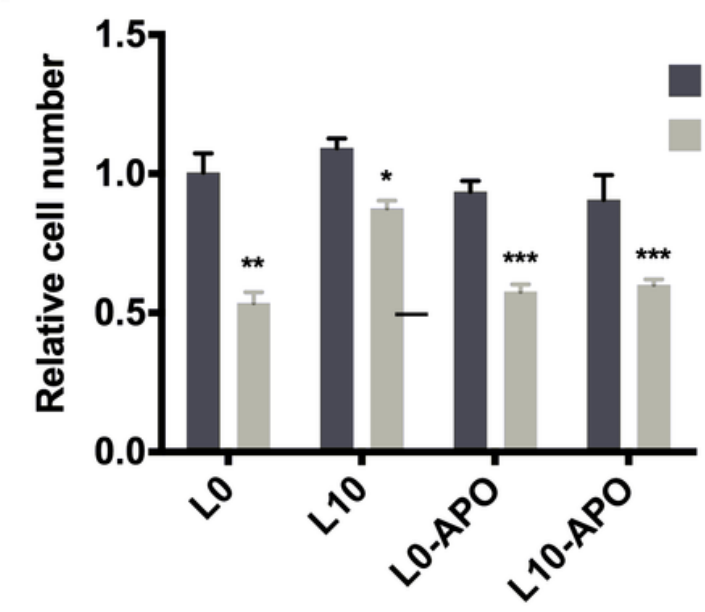

C

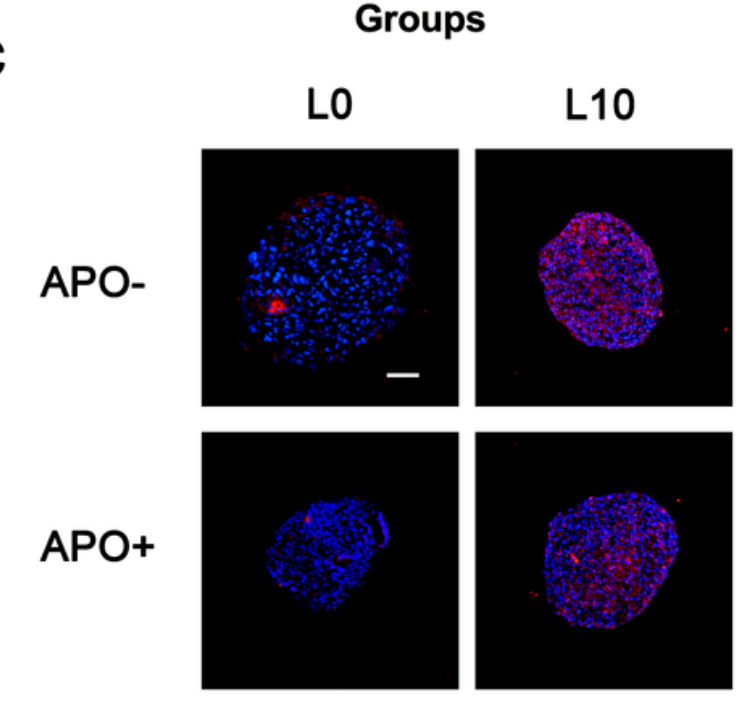

\section{Groups}

b

Post-conditioning

Post-transplantation
LO

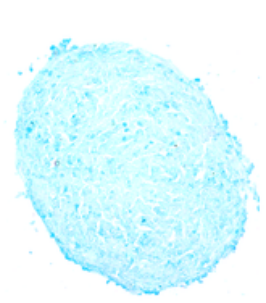

APO+

d

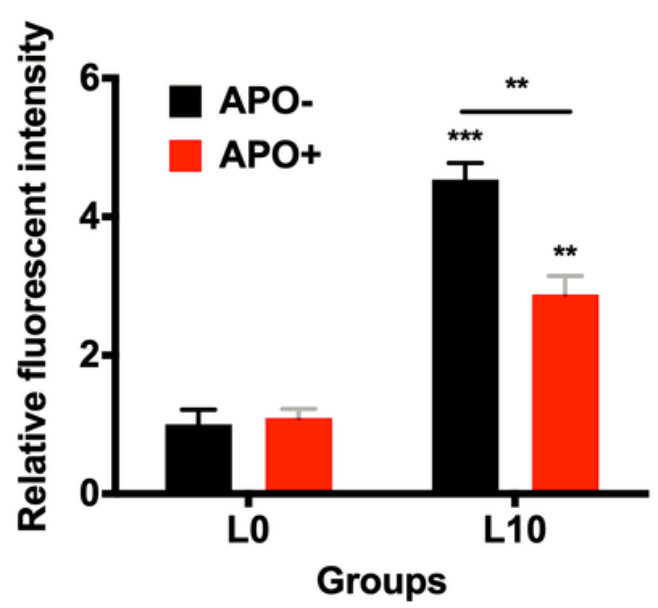

Figure 7

APO attenuated the effects of preconditioning using LiCl to ADSC. (a) Relative cell number of ADSC microsphere. (b) The ECM content of ADSC microspheres determined using Alcian Blue staining, scale bar $=50 \mu \mathrm{m}$. (c) The immunofluorescent staining of aggrecan in ADSC microspheres, scale bar $=50 \mu \mathrm{m}$. (d) Quantitative analyses of aggrecan content. Error bars depict Mean \pm SD. ( ${ }^{\star \star \star} P<0.001$, $* * P<0.01$, *P $<$ 0.05.) 
a

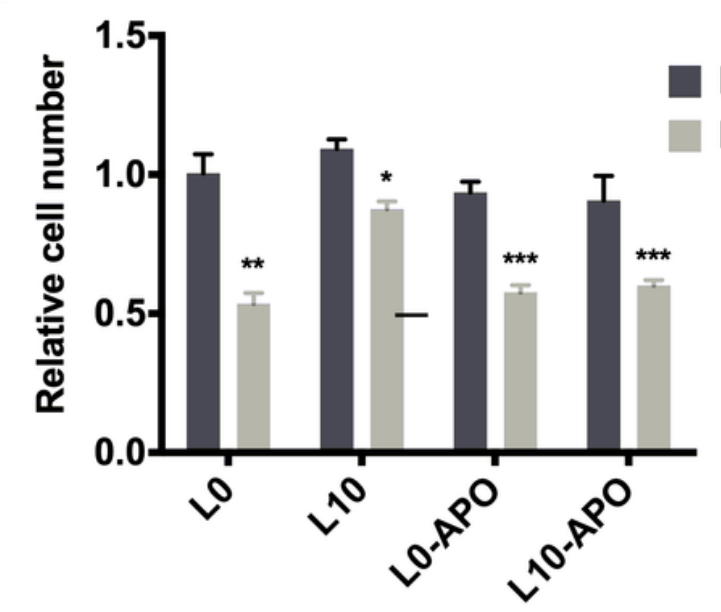

C

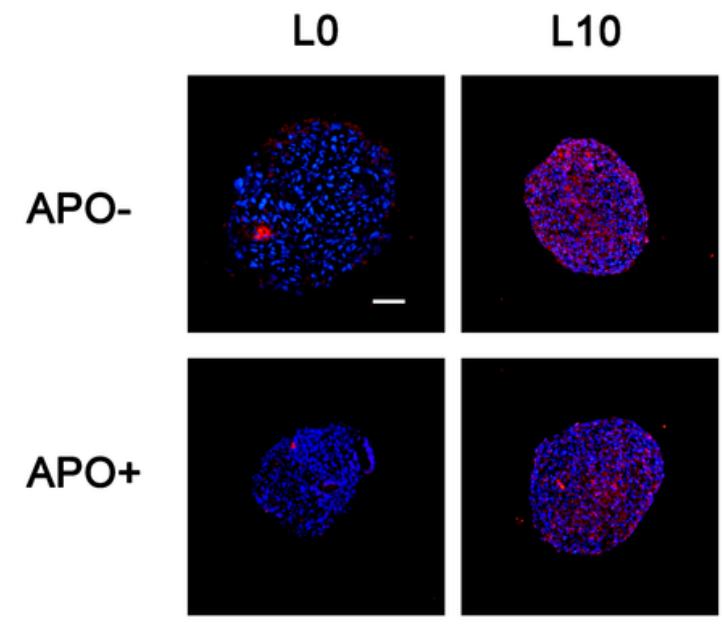

Groups

LO

L10 b

Post-conditioning

Post-transplantation
LO L10

APO-

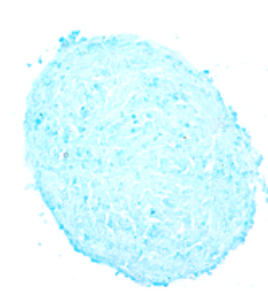

APO+

d

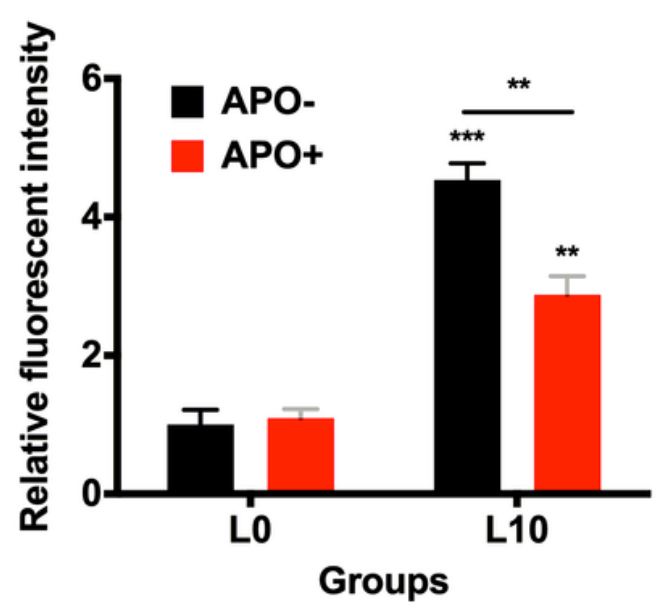

Figure 7

APO attenuated the effects of preconditioning using LiCl to ADSC. (a) Relative cell number of ADSC microsphere. (b) The ECM content of ADSC microspheres determined using Alcian Blue staining, scale bar $=50 \mu \mathrm{m}$. (c) The immunofluorescent staining of aggrecan in ADSC microspheres, scale bar $=50 \mu \mathrm{m}$. (d) Quantitative analyses of aggrecan content. Error bars depict Mean \pm SD. ( ${ }^{\star * * P}<0.001$, ${ }^{\star *} P<0.01$, ${ }^{*} P<$ 0.05.) 